\title{
Metal Matrix Composite in Heat Sink Application: Reinforcement, Processing, and Properties
}

\author{
Mirza Murtuza Ali Baig ${ }^{1}\left(\mathbb{D}\right.$, Syed Fida Hassan ${ }^{1,2, *(\mathbb{D})}$, Nouari Saheb ${ }^{1,2}$ and Faheemuddin Patel $^{1}$ (D) \\ 1 Department of Mechanical Engineering, King Fahd University of Petroleum and Minerals, \\ Dhahran 31261, Saudi Arabia; mmurtuza@kfupm.edu.sa (M.M.A.B.); nouari@kfupm.edu.sa (N.S.); \\ faheemmp@kfupm.edu.sa (F.P.) \\ 2 Interdisciplinary Research Center for Advanced Materials, King Fahd University of Petroleum and Minerals, \\ Dhahran 31261, Saudi Arabia \\ * Correspondence: sfhassan@kfupm.edu.sa; Tel.: +966-13-860-7787; Fax: +966-13-860-2949
}

check for updates

Citation: Baig, M.M.A.; Hassan, S.F.; Saheb, N.; Patel, F. Metal Matrix Composite in Heat Sink Application: Reinforcement, Processing, and Properties. Materials 2021, 14, 6257. https://doi.org/10.3390/ma14216257

Academic Editor: A

Javier Sanchez-Herencia

Received: 5 September 2021

Accepted: 28 September 2021

Published: 21 October 2021

Publisher's Note: MDPI stays neutral with regard to jurisdictional claims in published maps and institutional affiliations.

Copyright: (c) 2021 by the authors. Licensee MDPI, Basel, Switzerland. This article is an open access article distributed under the terms and conditions of the Creative Commons Attribution (CC BY) license (https:/ / creativecommons.org/licenses/by/ $4.0 /)$.

\begin{abstract}
Heat sinks are commonly used for cooling electronic devices and high-power electrical systems. The ever-increasing performance of electronic systems together with miniaturization calls for better heat dissipation. Therefore, the heat sink materials should not only have high thermal conductivities, low densities, and cost, but also have coefficients of thermal expansion matching to those of semiconductor chips and ceramic substrates. As traditional materials fail to meet these requirements, new composite materials have been developed with a major focus on metal matrix composites (MMCs). MMCs can be tailored to obtain the desired combination of properties by selecting proper metallic matrix and optimizing the size and type, volume fraction, and distribution pattern of the reinforcements. Hence, the current review comprehensively summarizes different studies on enhancing the thermal performance of metallic matrices using several types of reinforcements and their combinations to produce composites. Special attention is paid to the types of commonly used metallic matrices and reinforcements, processing techniques adopted, and the effects of each of these reinforcements (and their combinations) on the thermal properties of the developed composite. Focus is also placed on highlighting the significance of interfacial bonding in achieving optimum thermal performance and the techniques to improve interfacial bonding.
\end{abstract}

Keywords: metal matrix composite; heat-sink; aluminum matrix composite; reinforcement

\section{Introduction}

Heat sinks are commonly used for cooling electronic devices and high-power electrical systems [1]. Chingulpitak et al. [2] and Ahmed et al. [3] defined heat sink as "a type of heat exchanger used as a cooling system in electronic component". Pawar et al. [4] consider heat sink as an "environment or object that absorbs and dissipates heat from another object using thermal contact (either direct or radiant)". The advantages of the heat sink are low initial cost, simple installation, and a reliable manufacturing process [2,5]. They are widely used in cooling of electronic equipment and/or components including microprocessors, power modules, lasers, light-emitting diodes (LEDs), plasma and liquid crystal displays (LCDs and thermoelectric coolers (TECs) [4,6,7].

Microelectronics systems find wide application in today's world, ranging from digital watches to supercomputers [8]. The incessant growth in microelectronic systems has been driven by an insatiable quest for 'faster-smaller-cheaper' devices [9,10]. As the speed and operating frequency of the chip increases, the power dissipation goes up [3,8]. A reduction in 'interconnection-delays' by densely packing these chips and also hundreds of millions of transistors on a very small area on each chip enhances the performance further [8]. This comes with a penalty of an increase in the power density at the chip and module levels [8,11-17]. Therefore, the speed increases and the volume reduces at the expense of heat generation $[3,6,8,14-16,18]$. The temperature of the device will rise if the heat is not 
dissipated at a rate greater than the generation rate. Consequently, the effective life of the component is reduced $[3,4,6,11,14,19,20]$. In total, $55 \%$ of microelectronics failure are reported to be due to higher operating temperatures $[1,11,19]$. The effective containment of the operating temperature within the design limits can ensure a longer service life and reliable performance $[4,12]$. Therefore, the demand for improved thermal management solutions in microelectronic packaging has received intense research focus.

Figure 1 shows a schematic arrangement of the high-performance processor package. The package consists of an integrated heat spreader that is attached adhesively or soldered to the chip using a thermal interface material. The heat spreader spreads the heat from the chip to a wider area heat sink through a thermal interface material. Finally, the heat is dissipated from the heat sink fins to the surroundings [21].

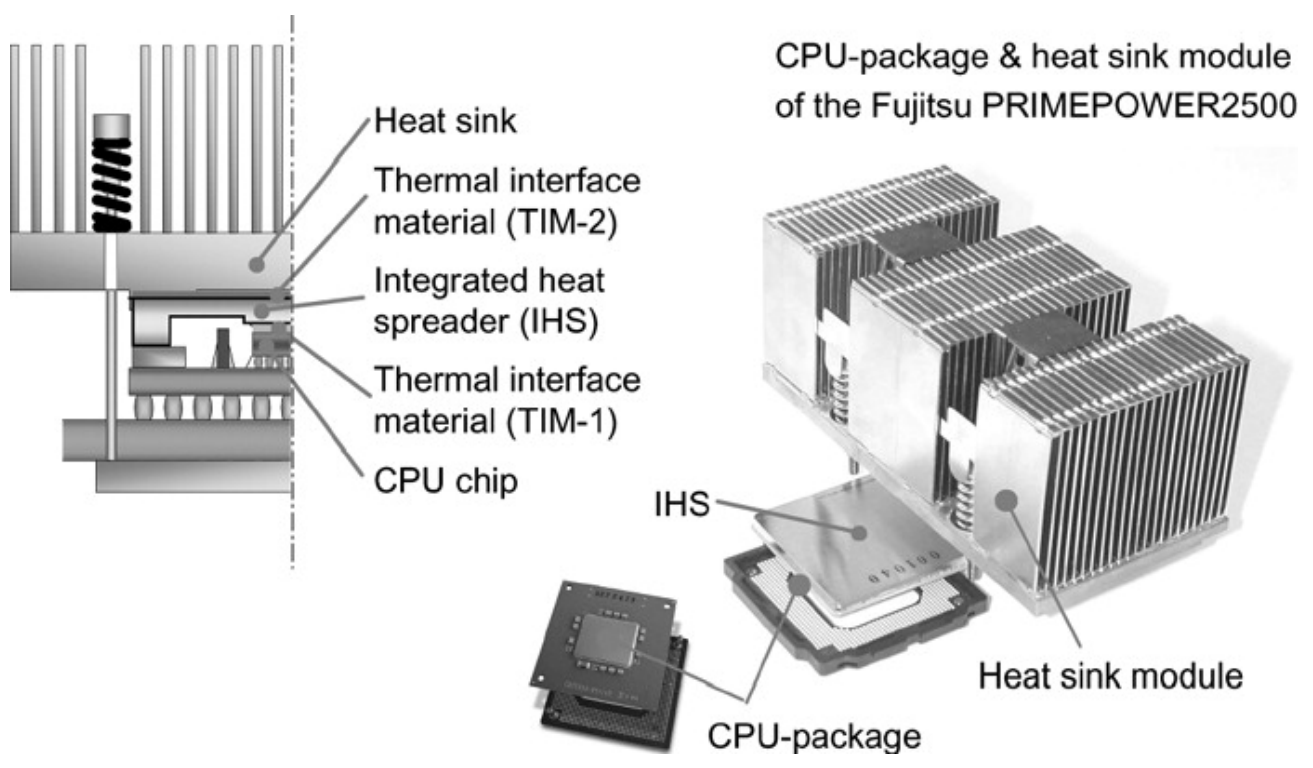

Figure 1. A typical structure of the CPU package and heat sink module [21].

The electronic systems have been continuously evolving following two important trends, namely 'enhanced performance' and 'miniaturization' [12,22]. The enhancement in performance is achieved at the expense of higher power densities, leading to a higher heat generation rate. To dissipate heat at a greater rate, the heat transfer area of the heat sink may be increased [23]. However, the resulting increase in size and weight is against the miniaturization trend $[23,24]$ and can induce mechanical stresses in the attached components [12,23,24]. Moreover, the end cost may be higher [23]. Therefore, the heat sink materials should not only have high thermal conductivities $[3,7,11,12,21]$ but also be lighter and cheaper $[4,7,12,15]$. Since the semiconductor chips and ceramic substrate have low coefficients of thermal expansion (i.e., between $3 \times 10^{-6} \mathrm{~K}^{-1}$ and $7 \times 10^{-6} \mathrm{~K}^{-1}$ ) [11], heat sinks must also match those $[6,7,11,21]$. Traditionally, $\mathrm{Cu}, \mathrm{Al}, \mathrm{Cu}-\mathrm{Mo}$, and $\mathrm{Cu}-\mathrm{W}$ blends; $\mathrm{Cu}-\mathrm{Mo}-\mathrm{Cu}$ and $\mathrm{Cu}-\mathrm{Invar}$ (64Fe-36Ni) laminates; and Invar and Kovar (53Fe-29Ni-17Co) alloys have been used as heat sink materials $[15,25]$. Al and $\mathrm{Cu}$ have an unacceptably high coefficient of thermal expansion, which induces thermal stresses, leading to brittle fracture of ceramic substrates. Tungsten and Molybdenum have high densities while Invar and Kovar alloys have poor thermal conductivity and high cost. As traditional materials fail to meet all the requirements, new composite materials have been developed, with a major focus on metal matrix composites. Hence, the focus of this review paper is to comprehensively summarize the types of commonly used reinforcements, processing techniques adopted, and the effects of each of these reinforcements (and their combinations) on the thermal properties of the developed composite. 


\section{Metal Matrix Composites}

Metal matrix composites (MMCs) are a type of composite in which, typically, the ceramic reinforcements are embedded in a metallic or alloy matrices [22,26-28]. MMCs can be tailored to combine metallic properties (high thermal conductivity, small density, toughness, ductility) with ceramic characteristics (low coefficient of thermal expansion, high strength and modulus), making them the most appropriate candidate as a heat sink material $[11,22,25-34]$. The desired combination of thermal conductivity and coefficient of thermal expansion can be obtained by optimizing the size and type, volume fraction, and distribution pattern of the reinforcements $[31,34,35]$.The different types of matrix materials and reinforcements used for heat sink applications are presented in Figure 2.

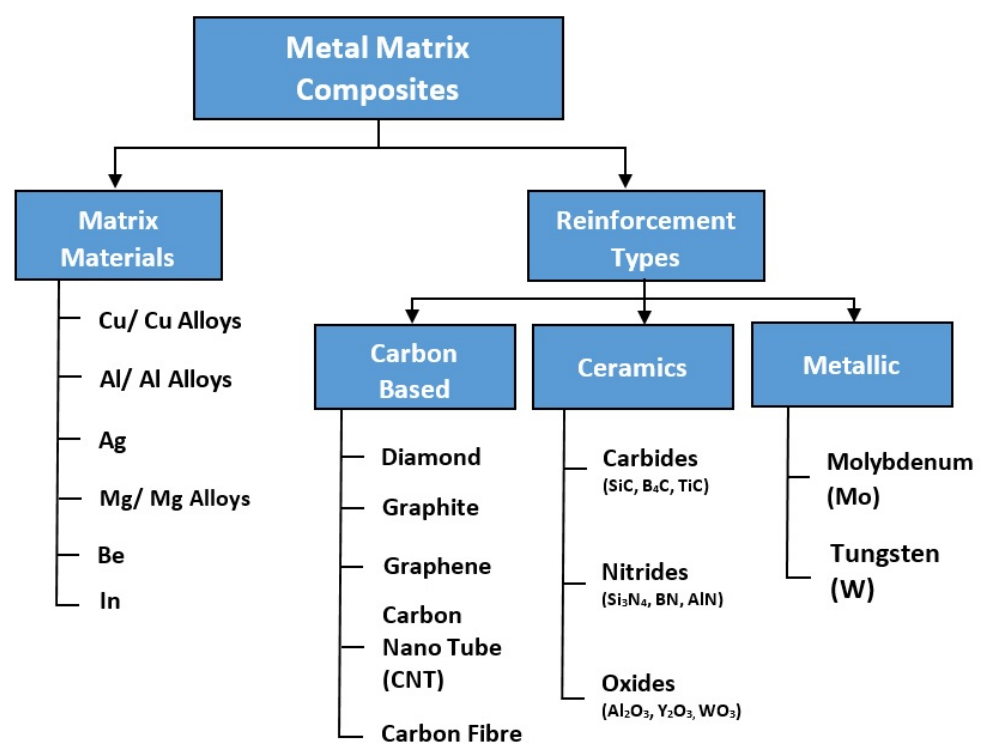

Figure 2. Different types of matrix materials and reinforcements used for heat sink applications.

\subsection{Copper Matrix Composites}

Copper is the most widely used matrix material for heat sink applications due to its high thermal conductivity $\left(400 \mathrm{Wm}^{-1} \mathrm{~K}^{-1}\right)$, high melting temperature, and good weldability [36-45]. To overcome the high coefficient of thermal expansion of copper, different reinforcements have been incorporated in the copper matrix, namely diamond particles [36,38-41,44-67], graphite (particles, fibers, or foam) [44,68-70], carbon fibers (CFs) [39,54,71-73], carbon nanotubes (CNTs) [74,75], SiC (particles or fibers) $[37,71,76,77]$, tungsten (particles, fibers, or wires) [42,43,71,78,79], molybdenum particles [80], and a hybrid of $\mathrm{Y}_{2} \mathrm{O}_{3}$ and $\mathrm{WO}_{3}$ particles [81].

The achievement of desired thermal properties from the copper matrix composite is determined by the interface between the matrix and the reinforcement $[38,46,58,67,82-84]$. The formation of a weak interfacial bond due to the non-wettability of liquid copper and absence of chemical reactivity with carbon-based reinforcements (diamonds, carbon fibers, and graphite) results in high thermal resistance at the interface. Consequently, the thermal conductivity of such composites is low $[38,40,41,44,50,53-65,67,70,76,84-91]$. Two approaches have been adopted in the literature to improve interfacial bonding: alloying copper matrix and coating reinforcements with carbide-forming elements.

\subsubsection{Diamond Reinforcements}

Diamond-reinforced copper matrix composites have attracted the most interest of researchers due to their high thermal conductivity (up to $2200 \mathrm{Wm}^{-1} \mathrm{~K}^{-1}$ ) $[36,41]$ ) and low coefficient of thermal expansion $\left(2.3 \times 10^{-6} \mathrm{~K}^{-1}\right.$ [41]). To take full advantage of its excellent thermal properties, the copper matrix was primarily alloyed with carbideforming elements, such as $\mathrm{Zr}, \mathrm{Cr}, \mathrm{B}$, and Ti. The thermal conductivity of the composite 
first increases and then decreases with an increasing content of $\mathrm{Zr}, \mathrm{Cr}, \mathrm{B}$, and Ti as shown in Figure 3. He et al. [38] reported a maximum thermal conductivity of $677 \mathrm{Wm}^{-1} \mathrm{~K}^{-1}$ at $1 \mathrm{wt} \% \mathrm{Zr}$. Li et al. [65] and Wang et al. [46] reported a maximum thermal conductivity of $930 \mathrm{Wm}^{-1} \mathrm{~K}^{-1}$ at $0.5 \mathrm{wt} \% \mathrm{Zr}$. Bai et al. [62] found that the thermal conductivity of composite approaches $660 \mathrm{Wm}^{-1} \mathrm{~K}^{-1}$ at $5 \mathrm{wt} \% \mathrm{~B}$. Weber et al. [84] reported maximum thermal conductivities of 600 and $700 \mathrm{Wm}^{-1} \mathrm{~K}^{-1}$ at 0.005 at $\%$ and $2.5 \mathrm{at} \% \mathrm{Cr}$ and $\mathrm{B}$, respectively. Che et al. [54] obtained a maximum thermal conductivity of $670 \mathrm{Wm}^{-1} \mathrm{~K}^{-1}$ by alloying the matrix with $3 \mathrm{vol} \% \mathrm{Ti}$. It was observed that the concentration of alloying elements should be optimized to achieve the maximum value of thermal conductivity as shown in Figure 3. At lower concentrations, inadequate interfacial bonding due to the small size of interfacial carbides results in inferior thermal conductivity. At higher concentrations, the thermal resistance of the interfacial carbide adversely affects the thermal conductivity of the composite $[38,46,54,65,84]$. Moreover, the excess alloying elements will remain in the matrix unreacted and deteriorate the thermal conductivity of the composite $[40,53,54,60,64,84]$.

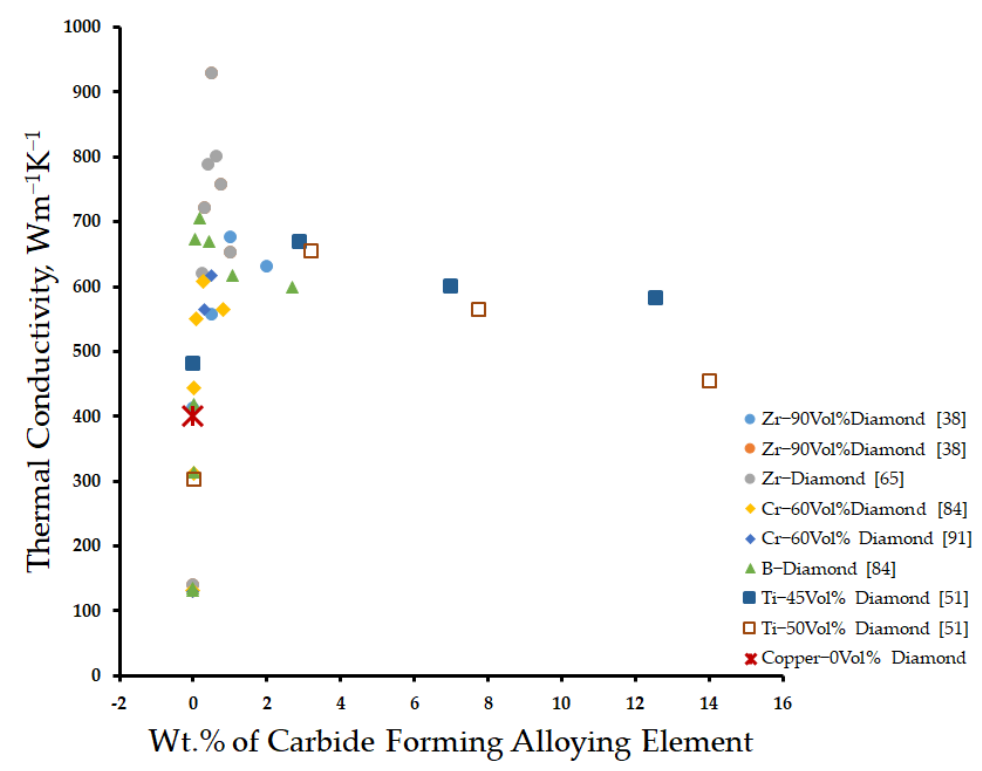

Figure 3. Effect of the content of carbide-forming alloying element in the copper matrix on the thermal conductivity of the composite.

The secondary approach to improve the interfacial bond between diamond particles and the copper matrix is the diamond surface modification. The carbide-forming elements, such as $\mathrm{B}, \mathrm{Ti}, \mathrm{W}, \mathrm{Cr}, \mathrm{Mo}$, or $\mathrm{Si}$, are deposited on the surface of diamond by magnetron sputtering [ $45,49,60,63]$, the molten salt method [40,41,48,53,67], the diffusion method [36,58,59], vacuum evaporation deposition [91], and electroless chemical deposition [52]. This coating serves as an intermediate layer that not only strengthens the interface between diamond and copper but also mitigates the degree of graphitization of diamond particles at elevated temperatures [53]. Figure 4 not only shows that the thermal conductivity improves with the application such coatings, but also that the larger thicknesses of those coatings can have an adverse effect. A thermal conductivity of $300 \mathrm{Wm}^{-1} \mathrm{~K}^{-1}$ for copper/diamond composite reinforced with (1.9 $\mu \mathrm{m}$ thick) $\mathrm{Cu}-0.5 \mathrm{~B}$-coated diamond particles was reported [45]. Maximum thermal conductivities of 811 [60] and $493 \mathrm{Wm}^{-1} \mathrm{~K}^{-1}$ [67] were reported for copper matrix composites reinforced with diamond particles with 220- and 285-nm-thick Ti coating, respectively. Abyzov et al. $[36,58,59]$ observed that the thermal conductivity of the copper/diamond composite increases from $500 \mathrm{Wm}^{-1} \mathrm{~K}^{-1}$ at 500 -nm-thick tungsten coating on diamond reinforcement to $900 \mathrm{Wm}^{-1} \mathrm{~K}^{-1}$ with the reduction in the coating thickness to $100 \mathrm{~nm}$. Kang et al. [40] synthesized a composite yielding a high thermal conductivity of $658 \mathrm{Wm}^{-1} \mathrm{~K}^{-1}$ by applying 1- $\mu \mathrm{m}$-thick WC coating on the diamond particulate reinforcement. Some researchers have reported thermal conductivities of 562 [41] and 
$596 \mathrm{Wm}^{-1} \mathrm{~K}^{-1}$ [53] accompanied with coefficients of thermal expansions of $7.8 \times 10^{-6} \mathrm{~K}^{-1}$ and $7.15 \times 10^{-6} \mathrm{~K}^{-1}$ with $\mathrm{Cr}_{7} \mathrm{C}_{3}$ - and $\mathrm{Mo}_{2} \mathrm{C}$-coated diamond particulate-reinforced copper matrix composites. Zhu et al. [92] reinforced Si-coated diamond particles into copper matrix to obtain a thermal conductivity of $535 \mathrm{Wm}^{-1} \mathrm{~K}^{-1}$. Cho et al. [93] reinforced TiC-coated diamond particles into copper matrix to obtain a thermal conductivity of $557 \mathrm{Wm}^{-1} \mathrm{~K}^{-1}$. Chang et al. [49] demonstrated that though the intermediate carbide layer can potentially improve the interfacial thermal conductance, the large thickness and low crystallinity of the intermediate layer will have an adverse effect on the thermal conductivity. The increase in thickness from 10 to $20 \mathrm{~nm}$ of the intermediate TiC layer deposited on a diamond substrate at room temperature was found to reduce the interfacial thermal conductance from 29 to $19 \mathrm{MW} /\left(\mathrm{m}^{2} \cdot \mathrm{K}\right)$. On the other hand, an increase in the coating deposition temperature (10 nm thickness) to $873 \mathrm{~K}$ increased the interfacial thermal conductance from 29 to $85 \mathrm{MW} /\left(\mathrm{m}^{2} \cdot \mathrm{K}\right)$ due to the transformation of the intermediate TiC layer from an amorphous to crystalline state.

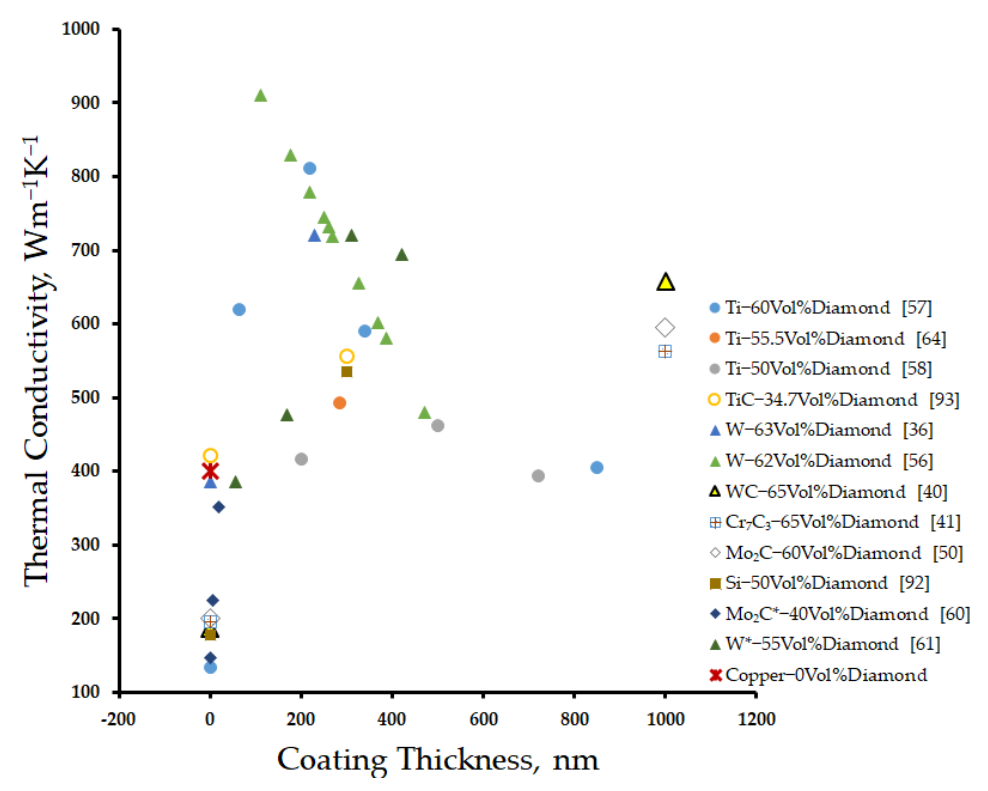

Figure 4. Effect of the carbide coating thickness on the diamond surface on the thermal conductivity of copper matrix composites.

Alternatively, some studies [61] have combined both the techniques by alloying copper matrix with $\mathrm{Ti}$ and modifying the diamond surface with a thin Ti coating. The particle composite system used to homogeneously blend $\mathrm{Cu}$-Ti powders caused the finer Ti particles to attach to the coarse $\mathrm{Cu}$ powders. The formation of the diamond/TiC/Ti/CuTi/Cu structure at the interface resulted in a thermal conductivity of $630 \mathrm{Wm}^{-1} \mathrm{~K}^{-1}$. In a similar study involving alloying matrix and coating diamond with $\mathrm{Cr}$, a thermal conductivity of $810 \mathrm{Wm}^{-1} \mathrm{~K}^{-1}$ was achieved [91]. In an attempt to avoid the usage of carbide-forming elements, diamond particles were coated with copper nanoparticles [39], but the maximum thermal conductivity that could be achieved was $460 \mathrm{Wm}^{-1} \mathrm{~K}^{-1}$. Some researchers have adopted a new technique of applying a dual layer coating on diamond particles with $\mathrm{W}[48,64]$ or Mo [63] as the inner layer and $\mathrm{Cu}$ as the outer layer. The resulting thermal conductivities were reported as 721,661 , and $351 \mathrm{Wm}^{-1} \mathrm{~K}^{-1}$, respectively. The advantages of this technique are a uniform distribution of diamond particles, lowering of the sintering temperature, and a very strong interfacial bond.

\subsubsection{Graphite Reinforcements}

High thermal conductivity ( $>900 \mathrm{Wm}^{-1} \mathrm{~K}^{-1}$ ), negative coefficient of thermal expansion $\left(-1.45 \times 10^{-6} \mathrm{~K}^{-1}\right)$, and low cost have made graphite fibers a potential reinforcement. The enhanced machinability of the composite is an additional advantage [70]. To improve 
interfacial bonding, they were coated with Cr. The inplane thermal conductivities and coefficients of thermal expansion were reported to range from $380-412 \mathrm{Wm}^{-1} \mathrm{~K}^{-1}$ and 6.1-9.4 $\times 10^{-6} \mathrm{~K}^{-1}$ [70]. In another study [44], the incorporation of graphite flakes resulted in a maximum thermal conductivity of $560 \mathrm{Wm}^{-1} \mathrm{~K}^{-1}$ perpendicular to the pressing direction. To obtain isotropic properties, $\mathrm{W}$-coated graphite particles were used as reinforcement, but the resulting thermal conductivity reported was just $158 \mathrm{Wm}^{-1} \mathrm{~K}^{-1}$ [69]. A composite presenting a combination of bulk thermal conductivity and coefficient of thermal expansion (i.e., around $342 \mathrm{Wm}^{-1} \mathrm{~K}^{-1}$ and $7.4 \times 10^{-6} \mathrm{~K}^{-1}$, respectively) suitable for heat sink application was obtained by infiltrating liquid copper into graphite foam [94].

\subsubsection{Carbon Fiber Reinforcements}

Carbon fibers have a thermal conductivity as high as $900 \mathrm{~W} / \mathrm{mK}$ and a negative coefficient of thermal expansion $\left(-0.6 \times 10^{-6} \mathrm{~K}^{-1}\right)$ along the fiber orientation. They were used as reinforcements to synthesize copper matrix composites for thermal management applications. Thermal conductivities of 220 and $120 \mathrm{Wm}^{-1} \mathrm{~K}^{-1}$ of unidirectional composites in the longitudinal and transverse direction, respectively, were reported by Korab et al. [72]. In a similar study [39], optimum thermal conductivities of 330 and $160 \mathrm{Wm}^{-1} \mathrm{~K}^{-1}$ in the longitudinal and transverse directions, respectively, were reported by incorporating $35 \%$ volume fraction pitch-type carbon fibers (K6371T) in the copper matrix. In order to overcome anisotropy in properties, cross-ply composites were fabricated, but the thermal conductivities obtained in the in-plane and transverse directions (i.e., 150 and $50 \mathrm{Wm}^{-1} \mathrm{~K}^{-1}$, respectively) were below $300 \mathrm{Wm}^{-1} \mathrm{~K}^{-1}$ [95]. Novel hydrothermal sintering successfully yielded an approximate isotropic thermal conductivity of $300 \mathrm{Wm}^{-1} \mathrm{~K}^{-1}$ with $40 \%$ volume fraction of copper-coated carbon fibers [73].

\subsubsection{Carbon Nanotubes (CNTs)}

CNTs possess outstanding thermal conductivity $\left(3000-6000 \mathrm{Wm}^{-1} \mathrm{~K}^{-1}\right)$ with an extraordinarily low coefficient of thermal expansion $\left(0 \times 10^{-6} \mathrm{~K}^{-1}\right)$, which can be exploited to achieve enhanced thermal performance. Unfortunately, retaining the thermal conductivity of matrix metal while incorporating CNTs has been a great challenge due to the inhomogeneous dispersion of CNTs. The formation of such clusters deteriorates the thermal conductivity of the composite [74]. A composite exhibiting a thermal conductivity and a coefficient of thermal expansion of $395 \mathrm{Wm}^{-1} \mathrm{~K}^{-1}$ and $5 \times 10^{-6} \mathrm{~K}^{-1}$, respectively, was successfully fabricated by filling copper in the pores of the macroscopic CNT [75].

\subsubsection{Graphene}

Graphene possesses outstanding in-plane thermal conductivity in the range of 1000-5300 $\mathrm{Wm}^{-1} \mathrm{~K}^{-1}$, and a through-plane thermal conductivity in the range of 5-20 Wm${ }^{-1} \mathrm{~K}^{-1}$. Moreover, it possesses a negative coefficient of thermal expansion of $-1.28 \times 10^{-6}$ to $-8 \times 10^{-6} \mathrm{~K}^{-1}[96,97]$. Though such outstanding properties make it an ideal reinforcement for MMCs intended for heat sink applications, its proper alignment is essential for an enhancement of its thermal performance. A thermal conductivity of $396 \mathrm{Wm}^{-1} \mathrm{~K}^{-1}$ was reported by reinforcing copper matrix with $0.3 \mathrm{wt} \%$ graphene by electrostatic self-assembly and powder metallurgy [98]. Chu et al. [96,97] developed an effective method to obtain copper matrix composites with highly aligned graphene reinforcements by using a vacuum filtration process followed by spark plasma sintering (SPS). Consequently, a copper matrix composite with $30 \mathrm{vol} \%$ graphene nanosheets yielded an in-plane thermal conductivity of $458 \mathrm{Wm}^{-1} \mathrm{~K}^{-1}$ along with a low through-plane coefficient of thermal expansion of $6.2 \times 10^{-6} \mathrm{~K}^{-1}$ [97]. In another study [96], $35 \mathrm{vol} \%$ graphene nanoplatelet reinforcement lead to a higher in-plane thermal conductivity of $525 \mathrm{Wm}^{-1} \mathrm{~K}^{-1}$. Graphene nano-sheets $(1 \mathrm{wt} \%)$ when added to $\mathrm{Cu} / \mathrm{WC}-\mathrm{TiC}-\mathrm{Co}$ composite improved its thermal conductivity from $190 \mathrm{Wm}^{-1} \mathrm{~K}^{-1}$ to $350 \mathrm{Wm}^{-1} \mathrm{~K}^{-1}$ [99]. The powder mix was coated with copper to ensure good interfacial bonding. 


\subsubsection{Silicon Carbide ( $\mathrm{SiC})$}

$\mathrm{SiC}$ possess a thermal conductivity and coefficient of thermal expansion of $200-300 \mathrm{Wm}^{-1} \mathrm{~K}^{-1}$ and $4.5 \times 10^{-6} \mathrm{~K}^{-1}$, respectively. Only a few researchers have focused on investigating the appropriateness of using $\mathrm{SiC}$ as a heat sink material. A maximum achieved thermal conductivity of $400 \mathrm{Wm}^{-1} \mathrm{~K}^{-1}$ was reported for a composite with $40 \%$ volume fraction $\mathrm{SiC}$ reinforcements [37]. Since $\mathrm{SiC}$ is unstable in copper at high temperatures, it is generally coated with W, Cr [76], and Mo [77]. A thermal conductivity of $306 \mathrm{Wm}^{-1} \mathrm{~K}^{-1}$ with a coefficient of thermal expansion of $11 \times 10^{-6} \mathrm{~K}^{-1}$ was reported with Mo-coated SiC particle inclusion in copper matrix [77].

\subsubsection{Metal Particles}

Tungsten (W) is specifically used as a reinforcement in $\mathrm{Cu}[42,43,78,79]$ or $\mathrm{CuCrZr}[36,43,71,100]$ matrix for heat sinks subjected to high heat flux. Since the composite is subjected to elevated temperatures, it must possess structural, mechanical, and thermal properties. The CuCrZr matrix composites reinforced with $30 \%$ and $50 \%$ volume fraction of $\mathrm{W}$ particles exhibited stable thermal conductivities of around 300 and $240 \mathrm{Wm}^{-1} \mathrm{~K}^{-1}$, respectively, over a temperature range of 300 to $600{ }^{\circ} \mathrm{C}$ [71]. The coefficient of thermal expansion of those composites was also found to stabilize in the range of 13.3 to $14.4 \times 10^{-6} \mathrm{~K}^{-1}$, and 9.7 to $10.3 \times 10^{-6} \mathrm{~K}^{-1}$ with $30 \%$ and $50 \%$ volume fraction $\mathrm{W}$ particle reinforcements, respectively, over a temperature range of 150 to $550{ }^{\circ} \mathrm{C}$. In another study, a composite with $60 \mathrm{wt} . \% \mathrm{~W}-40 \mathrm{wt} . \% \mathrm{Cu}$ showed stable thermal conductivity (260-240 $\mathrm{Wm}^{-1} \mathrm{~K}^{-1}$ ) over a temperature ranging from room temperature to $1000{ }^{\circ} \mathrm{C}$ [78].

Molybdenum (Mo) as a reinforcement has not received much research attention. Chen et al. [80] reported a thermal conductivity of $270 \mathrm{Wm}^{-1} \mathrm{~K}^{-1}$ with $55 \%$ volume fraction $\mathrm{Mo} / \mathrm{Cu}$ matrix composite.

\subsubsection{Metal Oxides}

Metal oxides as reinforcements have also been the least explored. Das et al. [81] used $\mathrm{Y}_{2} \mathrm{O}_{3}$ and $\mathrm{WO}_{3}$ to synthesize $\mathrm{Y}_{2} \mathrm{~W}_{3} \mathrm{O}_{12}$ hybrid powders. The thermal conductivities of all the composites with $40 \%$ to $70 \%$ volume fraction $\mathrm{Y}_{2} \mathrm{~W}_{3} \mathrm{O}_{12}$ reinforcements were below $300 \mathrm{Wm}^{-1} \mathrm{~K}^{-1}$.

Figure 5 presents an overview of the effectiveness of various reinforcements in improving the thermal conductivity of copper matrix composites. It can be observed that, in general, diamond particles serve as an effective reinforcement to significantly improve the thermal conductivity as compared to other reinforcements. Especially, the W coating on diamond particles proved to be consistently effective in rendering high thermal conductivity to the composites as evidenced from several studies $[36,40,48,55,56]$. Moreover, $\mathrm{Zr}$ is observed to be an effective carbide-forming element for alloying copper matrix. On the contrary, a general reduction in the thermal conductivity of the composite was observed compared to that of matrix material, with the incorporation of carbon fibers, CNT, W, and Mo reinforcements. However, a minimal improvement was observed in a plane where graphene reinforcements were aligned.

Figure 6 presents an overview of the effectiveness of various reinforcements in reducing the coefficient of thermal expansion of copper matrix composites. It can be observed that, in general, diamond particles serve as an effective reinforcement to significantly reduce the coefficient of thermal expansion as compared to other reinforcements $[41,53,59-61,63,65,84]$. The improved reinforcement-matrix interfacial bonding due to the alloying of copper matrices $[65,84]$ and/or by the surface metallization of diamond reinforcement $[41,53,59,60,63]$ with carbide-forming elements led to this improvement. Especially, Ti as a coating on diamond particles [60] and/or as an alloying element in copper matrix [61] proved to be effective in achieving a desired reduction in the coefficient of thermal expansion. 


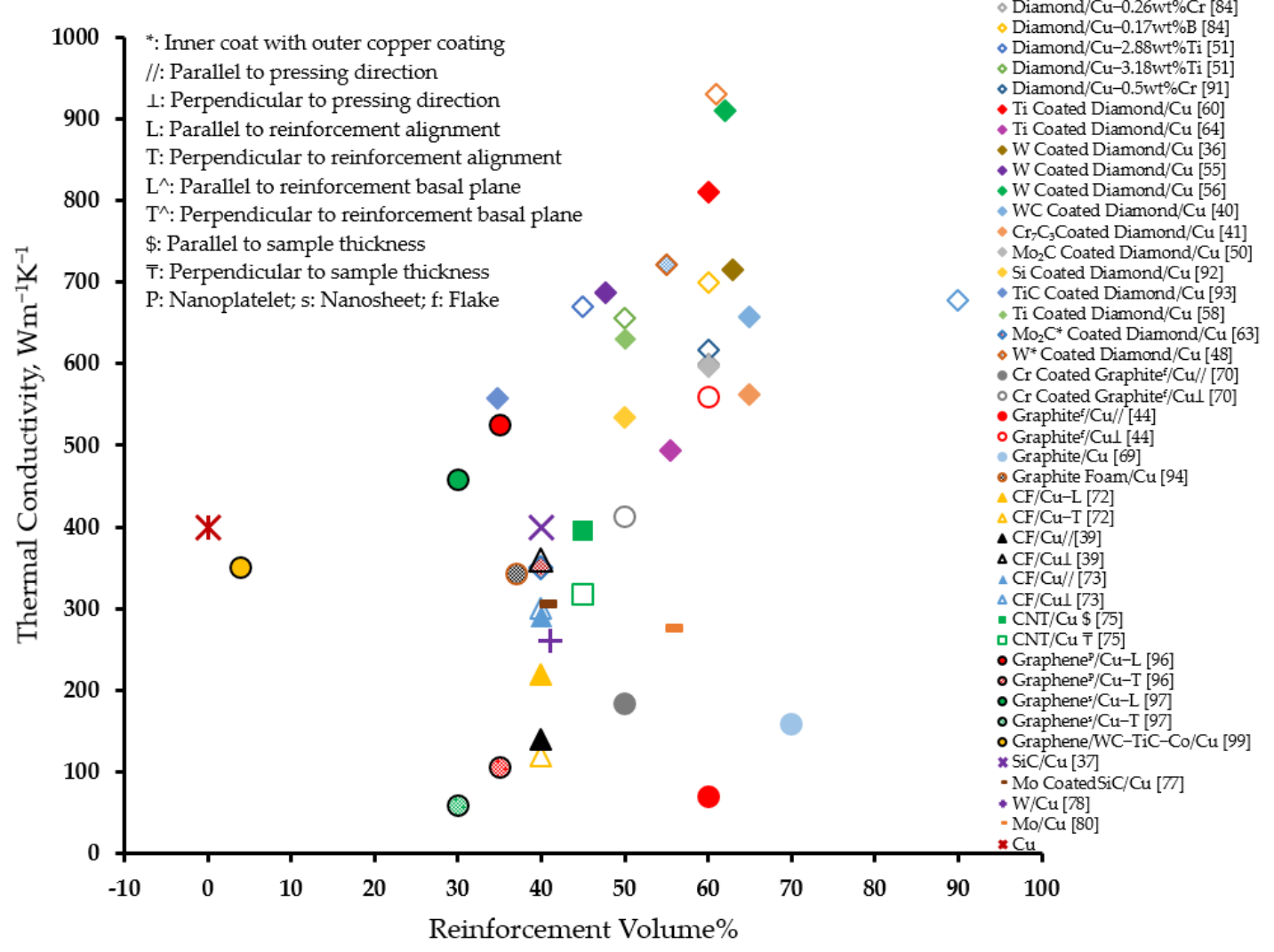

Figure 5. Effect of reinforcement on the thermal conductivity of copper matrix composites.

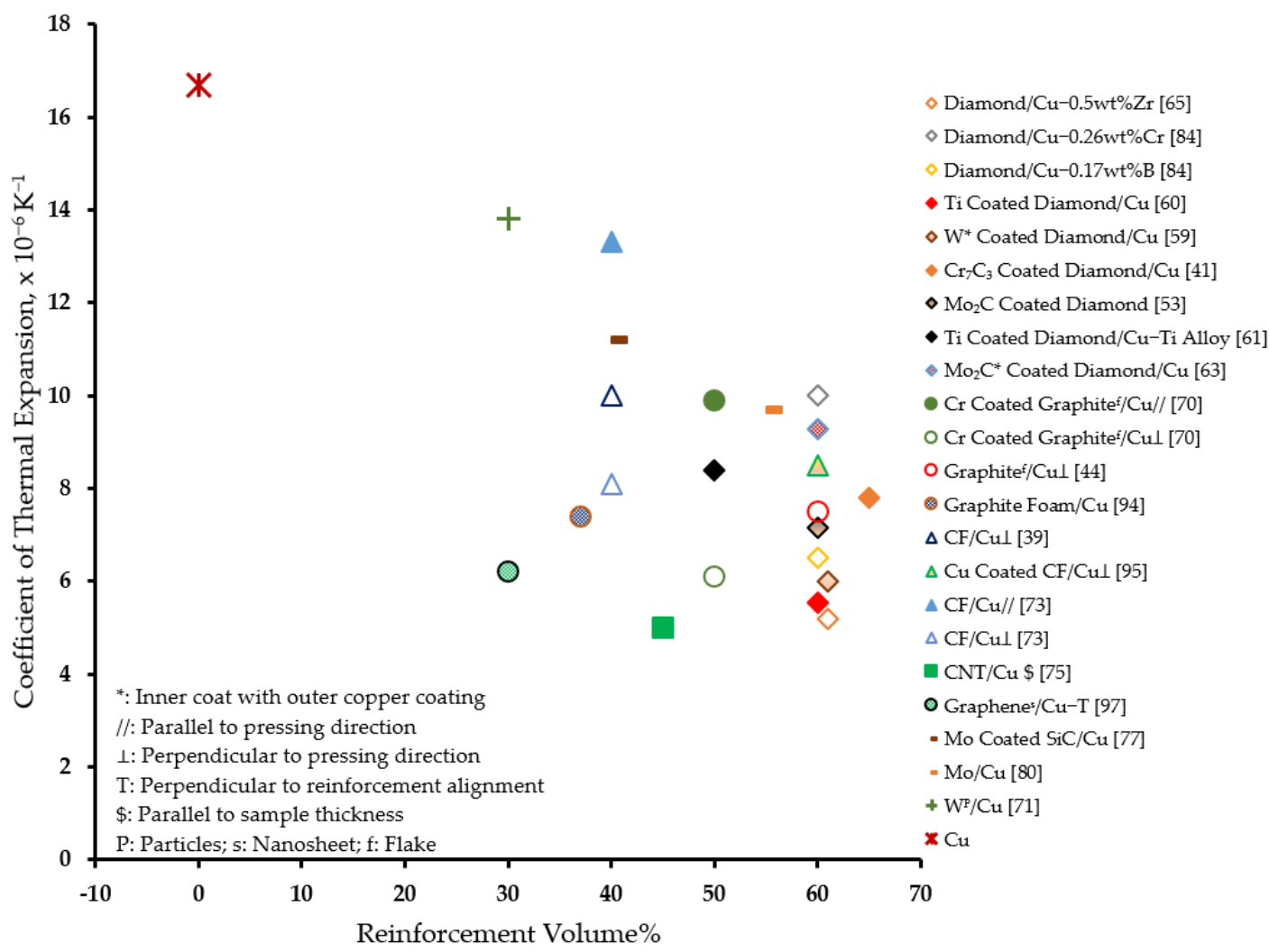

Figure 6. Effect of reinforcement on the coefficient of thermal expansion of copper matrix composites. 


\subsection{Aluminum Matrix Composites (AMCs)}

Aluminum, being lighter, has a high specific thermal conductivity, which makes it the leading matrix material for heat sink composites in automotive and aerospace electronics, and also in portable electronic devices [101-106]. However, the high coefficient of thermal expansion $\left(\sim 23 \times 10^{-6} \mathrm{~K}^{-1}\right)$ of aluminum is compensated by reinforcement with carbides (SiC [33,101,107-112], $\mathrm{B}_{4} \mathrm{C}$ [105]), nitride (BN [107,113], $\mathrm{Si}_{3} \mathrm{~N}_{4}$ [114], AlN [111,115]), oxides $\left(\mathrm{Al}_{2} \mathrm{O}_{3}\right.$ [107]), diamond [102,106,116-126], graphite flakes [68,127-129], and carbon fibers $[39,130-133]$.

\subsubsection{Carbide, Nitride, and Oxide reinforcements}

$\mathrm{SiC}$ is the most commonly used carbide reinforcement for aluminum matrix composites. Saraswati et al. [111] achieved an acceptable coefficient of thermal expansion $\left(7 \times 10^{-6} \mathrm{~K}^{-1}\right)$ along with a low thermal conductivity $\left(160 \mathrm{Wm}^{-1} \mathrm{~K}^{-1}\right)$. Zhang et al. [112] achieved an acceptable coefficient of thermal expansion $\left(7.3 \times 10^{-6} \mathrm{~K}^{-1}\right)$ with $73 \mathrm{vol} \%$ $\mathrm{SiC}$ particle-reinforced Al-Si alloy matrix. However, the resulting AMC suffered profound thermal fatigue damage as a result of thermal cycling. Schobel et al. [33] focused on the effect of void kinetics on the development of internal stresses and the resulting macroscopic thermal expansion behavior during thermal cycling of pure aluminum and Al-Si alloy matrix reinforced with $\mathrm{SiC}$ particles. The thermal fatigue damage was more profound in pure aluminum matrix than in Al-Si alloy matrix. Elomari et al. [109] demonstrated that the preoxidation of $\mathrm{SiC}$ can enhance the thermal performance of the composite at elevated temperatures. The enhanced performance was attributed to enhancement in the volume fraction of the ceramic phase from 47 to $55 \%$ due to the formation of a silicion oxide layer on its surface. The reinforcement of Al-Si alloy matrix with bimodal SiC particles resulted in enhanced thermal conductivity of the composite [110]. The increment in the volume fraction of finer particles reduces the micro-pores and sintering time. This favors the formation of new phases $\left(\mathrm{Al}_{9} \mathrm{Si}\right.$ and $\left.\mathrm{Al}_{3 \cdot 21} \mathrm{Si}_{0 \cdot 47}\right)$, which contributes to the increment of the thermal conductivity. The maximum thermal conductivity $\left(235 \mathrm{Wm}^{-1} \mathrm{~K}^{-1}\right)$ was reported at $45 \mathrm{vol} \%$ of finer $\mathrm{SiC}$ particles (i.e., $0 \mathrm{vol} \%$ larger $\mathrm{SiC}$ particles).

Manivannan et al. [107] developed AMCs reinforced with micron-sized 5 vol $\%$ cubic boron nitride $(\mathrm{CBN}), \mathrm{SiC}$, and $\mathrm{Al}_{2} \mathrm{O}_{3}$. A comparison of their thermal performance discovered that the $\mathrm{CBN}$ reinforcement yielded enhanced thermal conductivity, although the value remained relatively low for most applications. In another study, Manivannan et al. [113] reinforced AA (AA6061 T6) with micron-sized CBN particles. An improved thermal conductivity compared to the base alloy using a pin-fin apparatus was reported. Though CBN is considered to be one of the best conductors and is an abrasive, its potential as an efficient reinforcement to enhance the thermo-mechanical properties of AMCs has not been fully explored. The $\mathrm{B}_{4} \mathrm{C}$ and AlN-reinforced aluminum composites have not attracted much research focus. Tayebi et al. [105] reported the coefficient of thermal expansion to be $8 \times 10^{-6} \mathrm{~K}^{-1}$ with $\mathrm{Al} / 25 \% \mathrm{~B}_{4} \mathrm{C}$ composite. Zhang et al. [115] reported a thermal conductivity and coefficient of thermal expansion of $130 \mathrm{Wm}^{-1} \mathrm{~K}^{-1}$ and $11.2 \times 10^{-6} \mathrm{~K}^{-1}$ with $\mathrm{Al} / 50 \%$ AlN composite.

The efforts to develop aluminum nanocomposites for heat sink application is scarce. Matli et al. [114] fabricated $\mathrm{Al} / \mathrm{Si}_{3} \mathrm{~N}_{4}$ nanocomposite through the powder metallurgy route with subsequent microwave sintering and hot extrusion. A coefficient of thermal expansion of $19.3 \times 10^{-6} \mathrm{~K}^{-1}$ (reduction by $17.2 \%$ ) was reported. Reddy et al. [101] fabricated $\mathrm{Al} / \mathrm{SiC}$ nanocomposites through a similar route. A coefficient of thermal expansion of $19.2 \times 10^{-6} \mathrm{~K}^{-1}$ (reduction by $17.6 \%$ ) was reported. In both instances, the resulting coefficient of thermal expansion was above the acceptable range to meet market requirements.

\subsubsection{Carbon-Based Reinforcements}

Diamond forms weak interfacial bonds with $\mathrm{Al}$ matrix. Alloying matrix material with a small amount of $\mathrm{Si}$ was found to form $\mathrm{SiC}$ at the matrix-diamond interface. A thermal conductivity of $375 \mathrm{Wm}^{-1} \mathrm{~K}^{-1}$ and a coefficient of thermal expansion of $7 \times 10^{-6} \mathrm{~K}^{-1}$ 
was achieved with $\mathrm{AlSi} /$ diamond (60 vol\%) composite through the gas pressure infiltration route (GPI), where $\mathrm{SiC}$ was not formed at the interface [119]. The formation of a brittle, hydrophilic interfacial phase $\mathrm{Al}_{4} \mathrm{C}_{3}$ instead of $\mathrm{SiC}$ was considered to serve as a thermal barrier. To prevent the formation of $\mathrm{Al}_{4} \mathrm{C}_{3}$ and to improve interfacial bonding, the diamond particles were coated with $\mathrm{SiC}$ [121], $\mathrm{TiC}$ [116], $\mathrm{Ti}$ [123], and $\mathrm{W}$ [124]. A thermal conductivity of $365 \mathrm{Wm}^{-1} \mathrm{~K}^{-1}$ in combination with a low coefficient of thermal expansion of $5.69 \times 10^{-6} \mathrm{~K}^{-1}$ was reported with $60 \mathrm{vol} \%$ TiC-coated diamond particle reinforcement [116]. Yang et al. [123] fabricated AMC with Al-Si alloy matrix reinforced with Ti-coated diamond particles by gas pressure infiltration. The coefficient of thermal expansion was found to range between $5.07 \times 10^{-6} \mathrm{~K}^{-1}$ and $9.27 \times 10^{-6} \mathrm{~K}^{-1}$ with $50 \mathrm{vol} \%$ diamond particle reinforcement [123]. It is to be noted that the addition of a small amount of $\mathrm{Si}$ to $\mathrm{Al}$ reduces the propagation of thermal fatigue damage and helps to provide higher thermal stability in AMC [118]. Che et al. [124] reported an outstanding thermal conductivity of $620 \mathrm{Wm}^{-1} \mathrm{~K}^{-1}$ with gas pressure-infiltrated W-coated diamond-reinforced AMC.

Significant progress was realized when Ruch et al. [102] established the superiority of the gas pressure infiltration process over squeeze casting in the fabrication of $\mathrm{Al} /$ diamond composite. A thermal conductivity as low as $131 \mathrm{~W} / \mathrm{m}^{-1} \mathrm{~K}^{-1}$ of squeezecasted $\mathrm{Al} /$ diamond composite shot up to $670 \mathrm{~W} / \mathrm{m}^{-1} \mathrm{~K}^{-1}$ when fabricated by GPI. The characteristic long exposure time of diamond crystals to aluminum melt involved in this process promotes interfacial bonding and thermal conductance. Monje et al. [125] further explored the effect of the reinforcement-matrix melt contact time and infiltration temperature on the thermal conductivity of $\mathrm{Al} /$ diamond composite fabricated by the gas pressure infiltration process as presented in Figure 7. The higher the infiltration temperature, the shorter the contact time and vice-versa, which was observed to be required to attain maximum thermal conductivity. Maximum thermal conductivity of $636 \mathrm{Wm}^{-1} \mathrm{~K}^{-1}$ was reported at a contact time of $15 \mathrm{~min}$ and infiltration temperature of $760^{\circ} \mathrm{C}$. At the higher infiltration temperature of $850^{\circ} \mathrm{C}$, a maximum thermal conductivity of $676 \mathrm{Wm}^{-1} \mathrm{~K}^{-1}$ was achieved at a contact time of $1 \mathrm{~min}$ [125]. The enhanced thermal conductivity was due to the direct contact between the diamond surface and carbon-enriched Al layer (diffusion layer). The breaking away of the carbon atoms from the diamond surface and their subsequent diffusion through liquid $\mathrm{Al}$ results in the formation of the diffusion layer. The formation of the diffusion layer precedes the $\mathrm{Al}_{4} \mathrm{C}_{3}$ formation. After exceeding the solubility limit (43 atomic\%) of carbon in $\mathrm{Al}$, the $\mathrm{Al}_{4} \mathrm{C}_{3}$ phase precipitates on the diamond surface either in a particle form or as a continuous layer. For enhanced interfacial bonding and thermal conductance, the $\mathrm{Al} /$ diffusion layer/diamond system is preferred [125]. Zhang et al. [126] demonstrated that the process parameters can be optimized in the gas pressure infiltration process to achieve superior thermal conductivity of the $\mathrm{Al} /$ diamond composite by activating diffusion reaction on the diamond faces as shown in Figures 7 and 8 . The pressure optimization at infiltration temperatures as low as $750{ }^{\circ} \mathrm{C}$ can easily activate the diffusion reaction on the $\{100\}$ face of diamond. The $\{111\}$ face of diamond, being chemically more stable, requires higher energy levels to breakout carbon atoms from its surface. Therefore, to activate the diffusion reaction, this face requires temperature optimization. Moreover, higher infiltration temperatures require smaller pressure as shown in Figure 8. A thermal conductivity of $760 \mathrm{Wm}^{-1} \mathrm{~K}^{-1}$ was recorded at an optimum infiltration temperature and pressure of $800{ }^{\circ} \mathrm{C}$ and $0.8 \mathrm{MPa}$ [126]. Later, Wang et al. [106] also demonstrated that by controlling the processing parameters, squeeze casting can be used to obtain $\mathrm{Al} /$ diamond composites with a thermal conductivity of $606 \mathrm{Wm}^{-1} \mathrm{~K}^{-1}$. The enhanced thermal conductivity was attributed to the activation of the diffusion reaction on the $\{111\}$ face of diamond, resulting in good interfacial bonding and interfacial thermal conductance. Further studies are required to confirm the mechanism of improvement of thermal conductivity in $\mathrm{Al} /$ diamond composite and to explore the effect of $\mathrm{Al}_{4} \mathrm{C}_{3}$ on the thermal conductivity. 


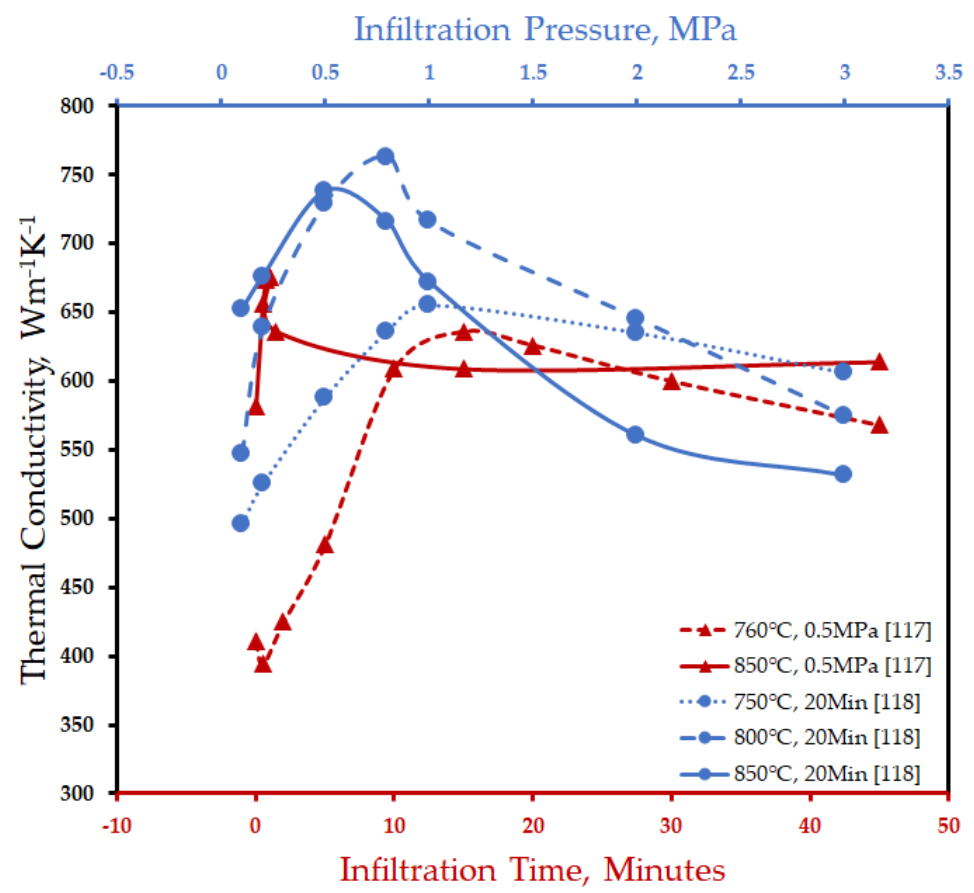

Figure 7. Effect of the infiltration temperature, time, and pressure on the thermal conductivity of AMCs fabricated by GPI.

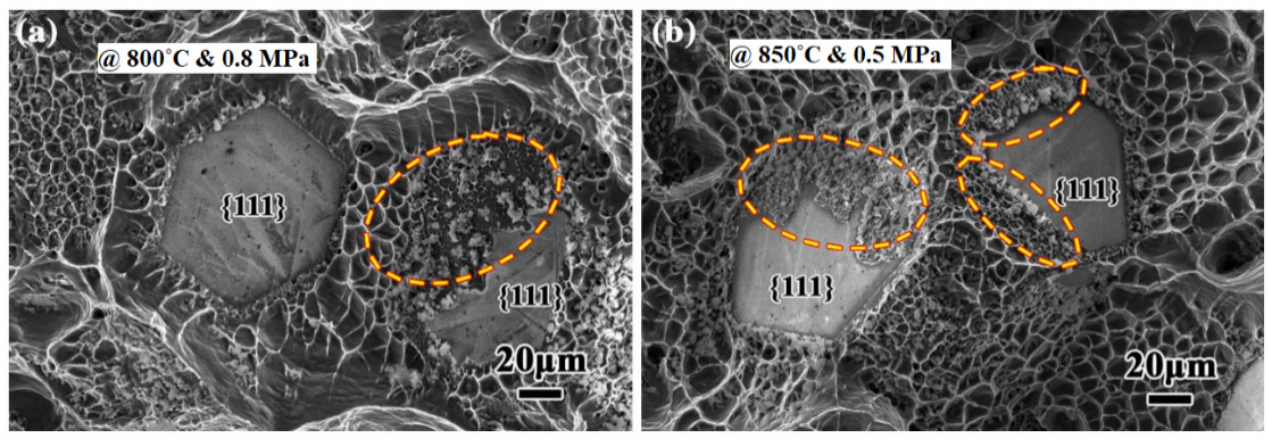

Figure 8. SEM micrographs demonstrating the occurrence of the diffusion reaction on the partial $\{111\}$ faces of diamond particles in the gas pressure-infiltrated $\mathrm{Al} /$ diamond composites: (a) $800{ }^{\circ} \mathrm{C}$ and $0.8 \mathrm{MPa}$; (b) $850{ }^{\circ} \mathrm{C}$ and $0.5 \mathrm{MPa}$ [126].

Some new approaches were adopted to reduce the usage of high-volume fraction of diamond reinforcement. Diamond film (6.5 vol\%) was coated on spiral $\mathrm{W}$ wire and was reinforced in the $\mathrm{Al}$ matrix, resulting in a thermal conductivity of $294 \mathrm{Wm}^{-1} \mathrm{~K}^{-1}$ [117]. A novel technique that has been reported is to infiltrate liquid $\mathrm{Al}$ into diamond-coated Cr-modified copper foam as shown in Figure 9. The resulting composite featured a thermal conductivity of $315.7 \mathrm{Wm}^{-1} \mathrm{~K}^{-1}$ at merely $4.6 \mathrm{vol} \%$ of diamond [134].

Graphite flake-reinforced Al matrix composites features excellent machinability in combination with high specific thermal conductivity. Oddone et al. [129] developed $50 \mathrm{vol} \%$ graphite flake-reinforced AMCs. A significantly high in-plane thermal conductivity $\left(390 \mathrm{Wm}^{-1} \mathrm{~K}^{-1}\right)$ with zero or negative through-plane CTE was reported. However, a drastic reduction in hardness and tensile strength with an increasing volume fraction of graphite flakes was noticed. An increase in thermal conductivity (from 324 to $783 \mathrm{Wm}^{-1} \mathrm{~K}^{-1}$ ) was reported with an increase in the volume percentage of graphite flakes (from 10 to $80 \%$ ) while the coefficient of thermal expansion reduced in the parallel (from 16.9 to $-2.5 \times 10^{-6} \mathrm{~K}^{-1}$ ) and perpendicular (from 15.2 to $10.1 \times 10^{-6} \mathrm{~K}^{-1}$ ) direction to the basal plane [127]. Additionally, an increase in the size of the graphite flakes can increase the thermal conductivity. 
The maximum thermal conductivity reported was $604 \mathrm{Wm}^{-1} \mathrm{~K}^{-1}$ with the increase in the size of the graphite flakes from 150 to $500 \mu \mathrm{m}$ [128]. These composites are commonly fabricated through the powder metallurgy route to avoid the formation of $\mathrm{Al}_{4} \mathrm{C}_{3}$, which reduces the thermal conductivity and corrosion resistance.

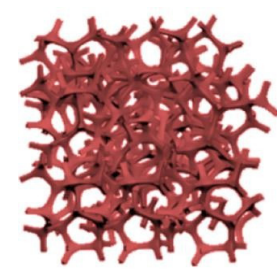

$\mathrm{Cu}$ foam

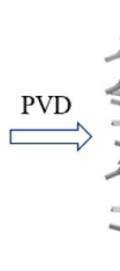

$\mathrm{Cr}$ modified $\mathrm{Cu}$ foam
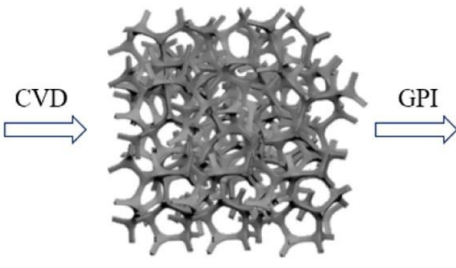

Diamond networks

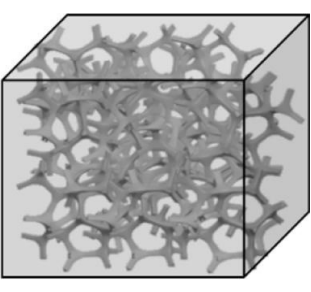

DN/Al composite

(A)

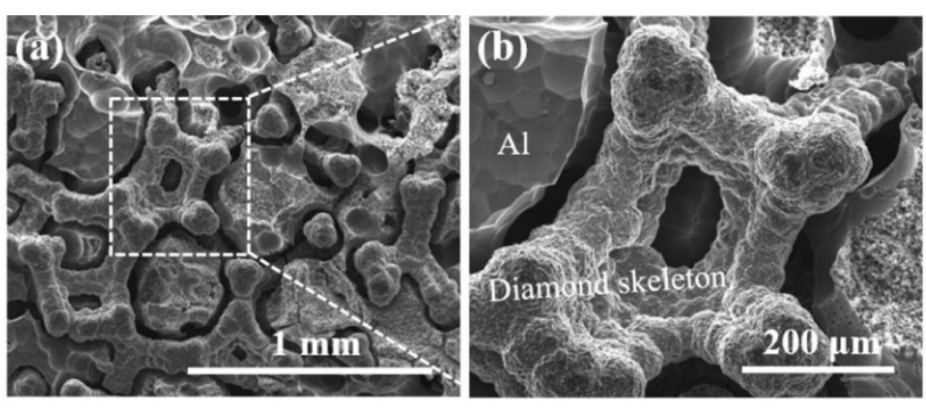

(B)

Figure 9. (A) Schematic illustration of the fabrication process of the diamond network/Al composite, (B) SEM morphologies of the diamond network/Al composite [134].

Another carbon-based reinforcement is carbon fiber. Beronska et al. [135] fabricated AMC by reinforcing $57.6 \mathrm{vol} \%$ unidirectional carbon fiber in $\mathrm{Al}-3 \mathrm{wt} \% \mathrm{Mg}$ alloy by the gas pressure infiltration process. $\mathrm{Mg}$ was added to suppress the formation of $\mathrm{Al}_{4} \mathrm{C}_{3}$. A thermal conductivity of $540.8 \mathrm{~W} / \mathrm{mK}$ in the longitudinal direction was reported. The coefficient of thermal expansion in the longitudinal direction was found to range from $-1 \times 10^{-6} \mathrm{~K}^{-1}$ to $-1.9 \times 10^{-6} \mathrm{~K}^{-1}$ with an increase in the temperature from 100 to $300{ }^{\circ} \mathrm{C}$. The enhanced thermal performance was attributed to the amorphous layer formed at the fiber-matrix interface in the presence of oxygen, which probably was absorbed during the infiltration. Lee et al. [136] reported a longitudinal thermal conductivity of $273.2 \mathrm{Wm}^{-1} \mathrm{~K}^{-1}$ with AMC reinforced with unidirectional carbon fiber fabricated by the low-pressure infiltration process. It was demonstrated that the growth rate of $\mathrm{Al}_{4} \mathrm{C}_{3}$ was more profound during the cooling than the infiltration process. The increase in time from 10 to $60 \mathrm{~min}$ to $\mathrm{cool}$ from 849 to $500{ }^{\circ} \mathrm{C}$ resulted in a decrease in the thermal conductivity from 273.2 to $230 \mathrm{Wm}^{-1} \mathrm{~K}^{-1}$, respectively. Silvain et al. [39] and Kurita et al. [131] reinforced aluminum matrix with $50 \mathrm{vol} \%$ carbon fibers. A small amount of Al-Si alloy ( $5 \mathrm{vol} \%$ ) was added to the aluminum matrix to reduce the melting point and improve the densification of the composite upon sintering. A in-plane thermal conductivity and coefficient of thermal expansion of $258 \mathrm{Wm}^{-1} \mathrm{~K}^{-1}$ and $7.09 \times 10^{-6} \mathrm{~K}^{-1}$, respectively, were reported. Tokunaga et al. [133] achieved a thermal conductivity of $323 \mathrm{Wm}^{-1} \mathrm{~K}^{-1}$ with $40 \mathrm{vol} \%$ reinforcement of carbon fibers in aluminum matrix with Al- 12.2 mass $\% \mathrm{Si}$ alloy (10 vol\%). Pei et al. [132] reinforced carbon fibers into AA6063 matrix. A thermal conductivity of $407 \mathrm{Wm}^{-1} \mathrm{~K}^{-1}$ along the fiber direction with a very low coefficient of thermal expansion between $-0.26 \times 10^{-6} \mathrm{~K}^{-1}$ and $0.26 \times 10^{-6} \mathrm{~K}^{-1}$ was reported.

Studies investigating the thermal performance of CNT-reinforced AMCs are scarce $[130,137]$. These studies focused on the contribution of CNTs to AMC based on theoretical analysis. Studies investigating the thermal performance of graphene-reinforced AMCs are also 
scarce. Zhang et al. [138] reported a thermal conductivity of $260 \mathrm{Wm}^{-1} \mathrm{~K}^{-1}$ with $0.3 \mathrm{wt} \%$ graphene-reinforced AMC fabricated by powder metallurgy.

Recently, hybridizing AMCs with secondary reinforcements to mitigate the side effects of adding primary reinforcements [103,139-142] and to make the resulting composite more suitable for the intended application has gained popularity. Shu et al. [103] hybridized aluminum matrix with $\mathrm{Ti}$ and $\mathrm{B}_{4} \mathrm{C}$ to form $\mathrm{TiC}_{\mathrm{x}}-\mathrm{TiB}_{2} / \mathrm{Al}$ composites. The resulting thermal conductivity was just $160 \mathrm{Wm}^{-1} \mathrm{~K}^{-1}$. Molina et al. [139] reported a thermal conductivity of $390 \mathrm{Wm}^{-1} \mathrm{~K}^{-1}$ by reinforcing $\mathrm{Al}-12 \mathrm{wt} \% \mathrm{Si}$ alloy matrix with graphite flakes and $\mathrm{SiC}$ particles. Chamroune et al. [140] hybridized aluminum matrix with graphite flakes and carbon fibers, featuring an in-plane thermal conductivity of $410 \mathrm{Wm}^{-1} \mathrm{~K}^{-1}$ with in-plane and through plane coefficients of thermal expansion of $15 \times 10^{-6} \mathrm{~K}^{-1}$ and $2.4 \times 10^{-6} \mathrm{~K}^{-1}$, respectively, using solid-liquid sintering. In another study, Peng et al. [141] reinforced graphite flakes and carbon fibers in aluminum matrix, yielding a thermal conductivity of $402 \mathrm{Wm}^{-1} \mathrm{~K}^{-1}$. Graphite flakes were coated with copper while the carbon fibers were doped with nitrogen to improve their wettability in Al matrix and the composite was fabricated through the optimized vacuum gas pressure infiltration method. Xue et al. [142] reported a thermal conductivity of $400 \mathrm{Wm}^{-1} \mathrm{~K}^{-1}$ and a coefficient of thermal conductivity of $7.8 \times 10^{-6} \mathrm{~K}^{-1}$ with diamond/SiC/ Al-7Si-0.3Mg hybrid AMC. Han et al. [143] reported a thermal conductivity of $482.14 \mathrm{Wm}^{-1} \mathrm{~K}^{-1}$ and a coefficient of thermal of $2.5 \times 10^{-6} \mathrm{~K}^{-1}$ by reinforcing aluminum matrix with $70 \mathrm{vol} \%$ graphite flakes, and 3-D copper networks coated with $5 \mathrm{vol} \%$ graphene. The enhanced thermal performance was attributed to the effective heat transfer path provided by copper networks and to the better distribution of graphite reinforcements.

Figure 10 presents an overview of the effectiveness of the various reinforcements in improving the thermal conductivity of aluminum matrix composites. It can be observed that, in general, diamond as well as graphite reinforcements are effective in significantly improving the thermal conductivity as compared to other reinforcements. In fact, graphite featured the highest thermal conductivity in the direction parallel to its basal plane. However, a heavy reinforcement loading in the range of $48 \mathrm{vol} \%$ to $80 \mathrm{vol} \%$ for graphite, and $58 \mathrm{vol} \%$ to $68 \mathrm{vol} \%$ for diamond was used to realize the aforementioned effect. Interestingly, a significantly high ratio of thermal conductivity to diamond loading was observed when a much smaller volume percentage of diamond was used in the fabrication of diamond network and diamond film-coated tungsten-reinforced AMCs, respectively [117,134]. On the contrary, a general reduction in the thermal conductivity of the composite was observed compared to that of the matrix material with the incorporation of $\mathrm{Al}_{2} \mathrm{O}_{3}, \mathrm{SiC}, \mathrm{BN}$, and $\mathrm{AlN}$ reinforcements. However, a minimal improvement was observed with reinforcement with graphene and carbon fibers.

Figure 11 presents an overview of the effectiveness of various reinforcements in reducing the coefficient of thermal expansion of aluminum matrix. It can be observed that, in general, diamond reinforcement is effective in significantly reducing the coefficient of thermal expansion as compared to other reinforcements $[116,119,123]$. Graphite reinforcement induced a very large anisotropy in the coefficient of thermal expansion of aluminum, ranging from a negative $[127,129]$ to unacceptably high $[129,140]$ values. On the other hand, hybrid AMCs present a desired reduction in the coefficient of thermal expansion $[142,143]$.

\subsection{Silver Matrix Composite}

Silver has the highest thermal conductivity $\left(429 \mathrm{Wm}^{-1} \mathrm{~K}^{-1}\right)$ among all the matrix materials considered for thermal management. Due to its scarcity and high cost, it has been rarely investigated. Zhao et al. [144] reported a thermal conductivity of $768 \mathrm{Wm}^{-1} \mathrm{~K}^{-1}$ by reinforcing silver matrix with $\mathrm{Cr}$-coated diamond particles. Pal et al. [145] studied the effect of functionalization of CNT reinforcement on the thermal conductivity of composite. The non-covalently functionalized CNTs resulted in a thermal conductivity of $530 \mathrm{Wm}^{-1} \mathrm{~K}^{-1}$ due to lower interfacial resistance. 


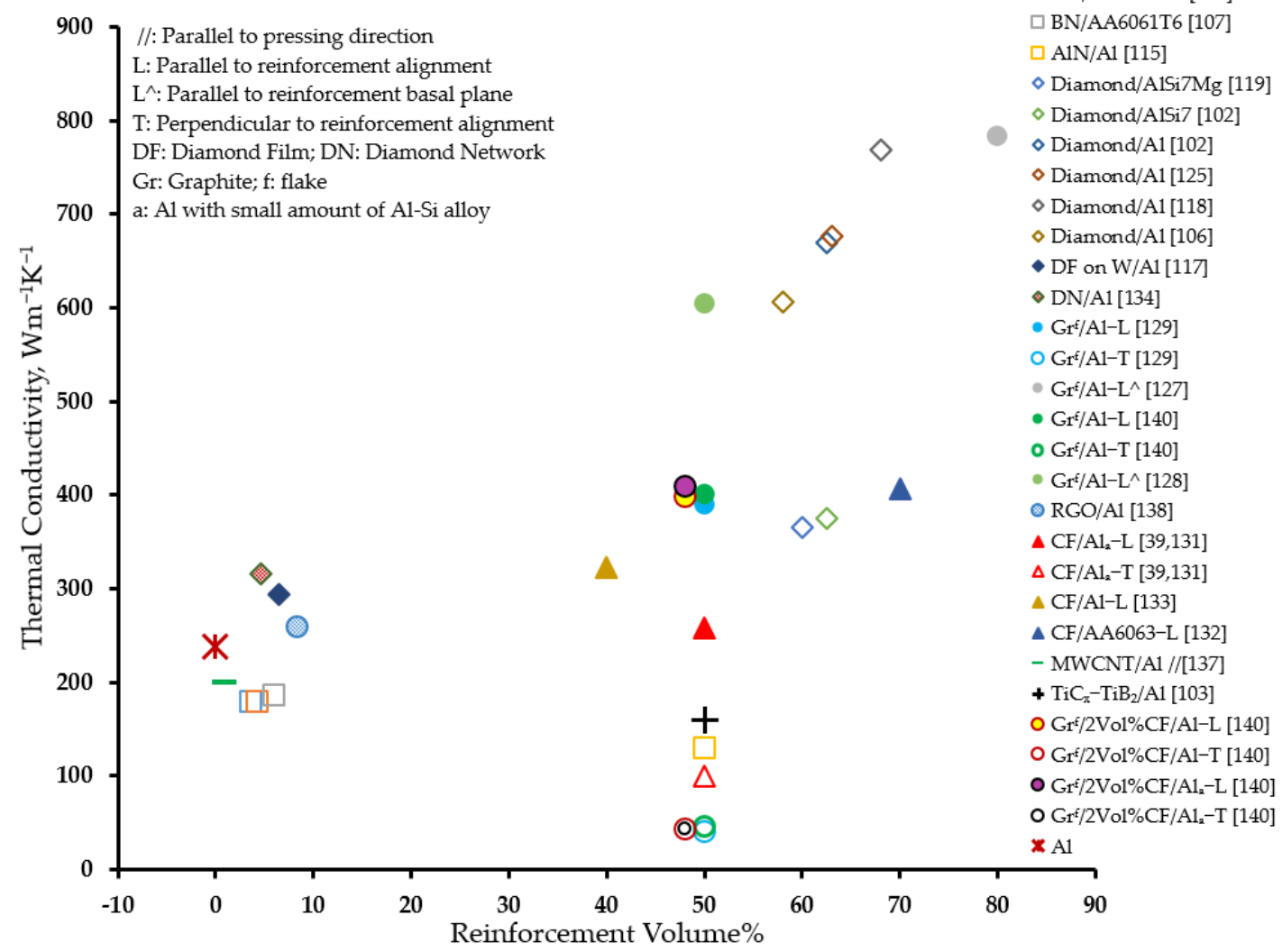

Figure 10. Effect of reinforcement on the thermal conductivity of AMCs.

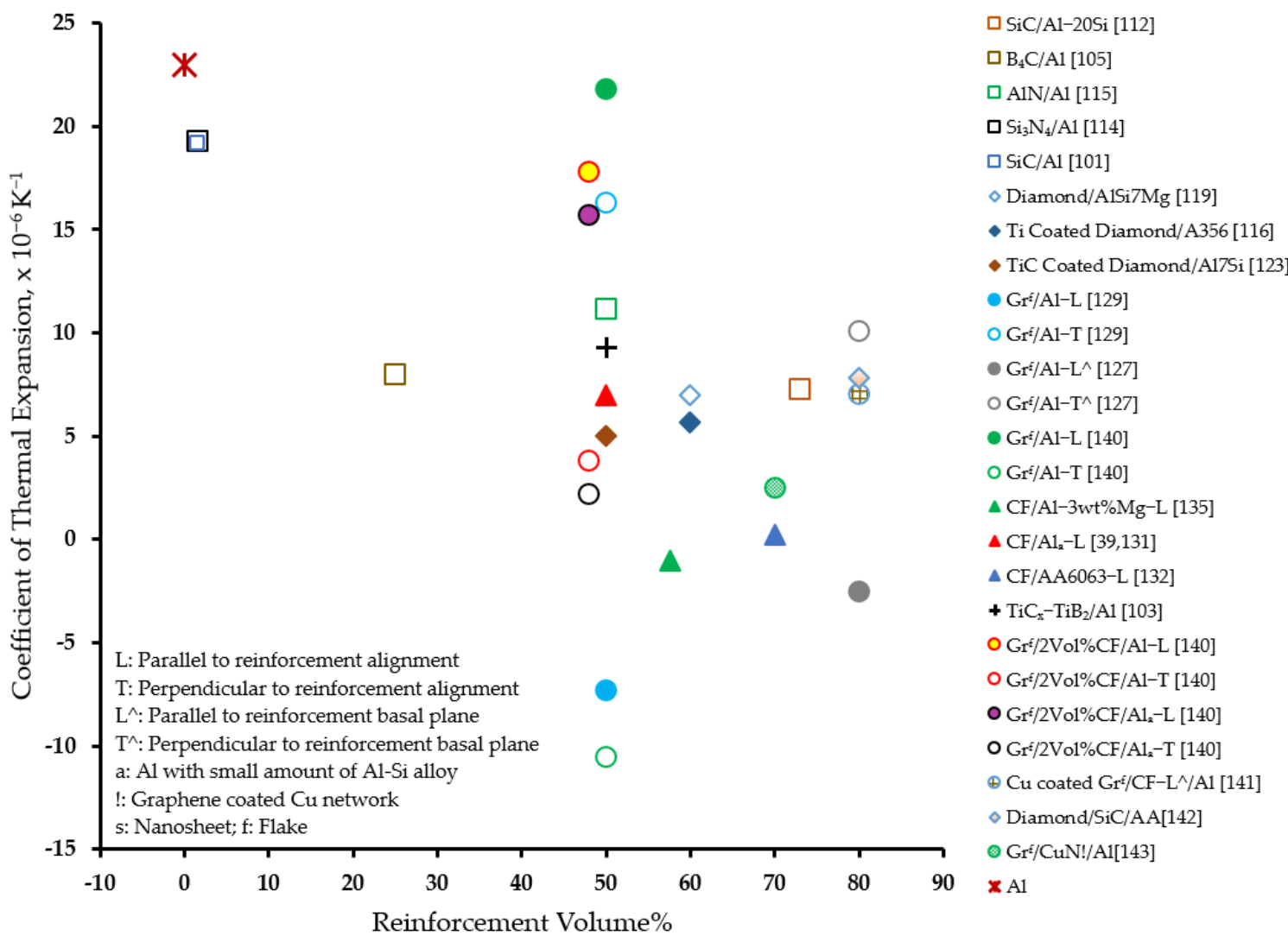

Figure 11. Effect of reinforcement on the coefficient of thermal expansion of AMCs. 


\subsection{Magnesium Matrix Composite}

Given the low thermal conductivity $\left(156 \mathrm{Wm}^{-1} \mathrm{~K}^{-1}\right)$ of magnesium, it has also rarely been explored for thermal applications. Molina et al. [146] reported a thermal conductivity of $716 \mathrm{Wm}^{-1} \mathrm{~K}^{-1}$ with TiC-coated bimodal diamond particle reinforcement. The enhancement in their thermal conductivity was attributed to the nano-scale coating thickness, and to the bimodal mixture of thee reinforcing particles. Hou et al. [147] reported a low thermal conductivity of $120.6 \mathrm{Wm}^{-1} \mathrm{~K}^{-1}$ with Ni-coated short carbon fiber (1 vol\%) reinforcement.

\subsection{Beryllium Matrix Composite}

Beryllium possesses a thermal conductivity of $200 \mathrm{Wm}^{-1} \mathrm{~K}^{-1}$ and a coefficient of thermal expansion of $9.5 \times 10^{-6} \mathrm{~K}^{-1}$. Parsonage et al. [148] fabricated a beryllium matrix composite reinforced with $\mathrm{BeO}$, but a marginal improvement in the thermal conductivity and coefficient of thermal expansion to $215 \mathrm{Wm}^{-1} \mathrm{~K}^{-1}$ and $8.7 \times 10^{-6} \mathrm{~K}^{-1}$, respectively, was reported.

\subsection{Indium Matrix Composite}

Zeng et al. [149] reinforced indium with $50 \mathrm{vol} \%$ diamond particles and achieved a maximum thermal conductivity of $211 \mathrm{Wm}^{-1} \mathrm{~K}^{-1}$.

\section{MMC Processing}

Metal matrix composites reinforced with particles, platelets, non-continuous, and continuous fibers are essentially produced in either the liquid state or in the solid state $[86,150,151]$. The most popular liquid state processing methods are stir casting and liquid metal infiltration while the solid state processing route is called powder metallurgy.

\subsection{Liquid State Processing}

This method enables the incorporation of high-volume fraction of reinforcements, which is imperative to obtain a low coefficient of thermal expansion along with high thermal conductivity of the composite.

\subsubsection{Stir Casting Process}

In this process, the reinforcements in the form of short fibers and particles are stirred into a molten metal prior to casting [22,25,81]. Manivannan et al. [107,113] used the bottom tapping stir casting method to fabricate AMCs. This method prevented oxide formation on the surface of the molten metal. The major limitation of this process is the inhomogeneous distribution of reinforcement caused by the density difference between the melt and the reinforcements $[22,25,107,113]$.

\subsubsection{Liquid Metal Infiltration}

Squeeze Casting

The reinforcing particles are first pressed in a mold to make a preform. The preform is preheated in a forming gas atmosphere $\left(94 \% \mathrm{Ar}\right.$ and $\left.6 \% \mathrm{H}_{2}\right)$. The preheat temperature depends on the type of reinforcement. Meanwhile, the matrix metal (aluminum or copper) is melted separately. The preform is placed inside a die preheated to a relatively much lower temperature. The molten metal is immediately poured with simultaneous application of vacuum to the preform and a predetermined vertical pressure to the melt. The infiltration of molten metal into the preform is caused by the downward pressure applied by a hydraulic or pneumatic piston. The applied pressure is determined such that the piston displacement rate completes the infiltration in a few seconds before the actual commencement of solidification. The relatively cold die aids in rapid solidification of the composite under the applied pressure. The casted samples are either air cooled or annealed followed by furnace cooling to room temperature $[22,25,86,150]$. A schematic diagram of a typical squeeze casting unit is shown in Figure 12. 


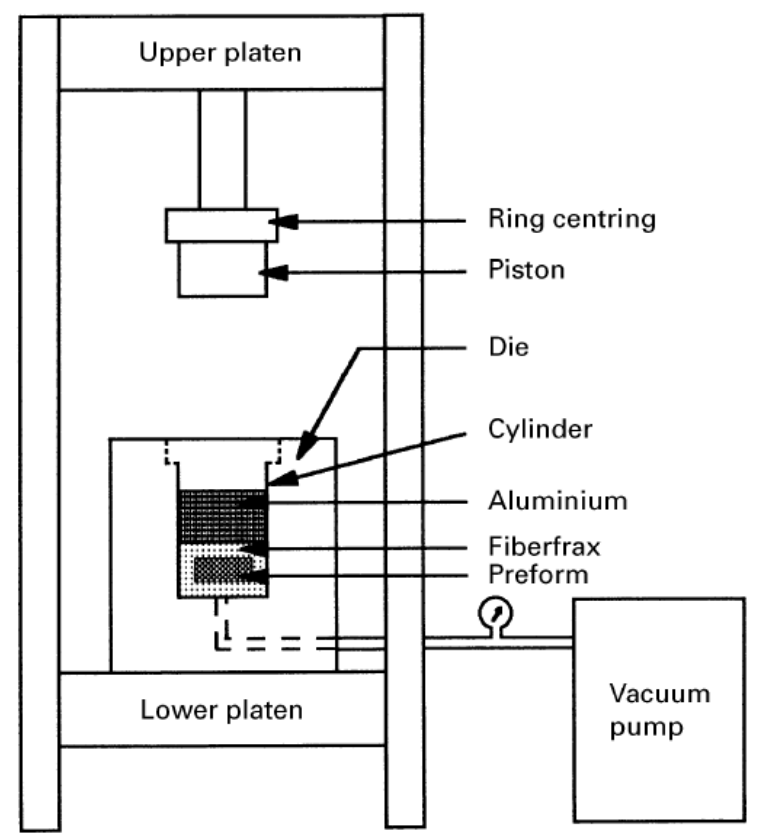

Figure 12. Schematic diagram of a squeeze casting unit [109].

The low-temperature processing ability along with rapid infiltration and solidification have made this technique more attractive for the fabrication of AMCs [80,106,109,120,132]. The infiltration and solidification times are too short for the formation of interfacial compound $\left(\mathrm{Al}_{4} \mathrm{C}_{3}\right)$. No graphitization of carbon fibers was observed in the fabrication of $\mathrm{AMC}$ by this method [132]. Neither the formation of interfacial $\mathrm{Al}_{4} \mathrm{C}_{3}$ nor any reaction between diamond reinforcements and Si when present in the AMC matrix were observed [102]. Rather, the addition of silicon adversely affected the coefficient of thermal expansion at high temperatures [112]. Though Khalid et al. [120] could avoid the formation of undesired $\mathrm{Al}_{4} \mathrm{C}_{3}$ during fabrication of AMC reinforced with monocrystalline diamond, a transformation of diamond particles into the amorphous carbon phase was reported. Pingping wang et al. [106] optimized the squeeze casting process by increasing the preheat and infiltration temperatures, and also the contact time between the diamond preform and the molten $\mathrm{Al}$ to promote the formation of the $\mathrm{Al}-\mathrm{C}$ diffusion layer. The in situ generated thin layer diffusion layer was demonstrated to improve the interfacial bond and thermal conductivity.

\section{Gas/ Vacuum Pressure Infiltration}

In this process, a pressurized inert gas or vacuum forces the molten metal/alloy in to the preform $[22,86,152]$. A gas pressure liquid infiltration apparatus is shown in Figure 13. The high-volume fraction reinforcement is tap packed in a steel cylinder, which is placed in the upper chamber. Aluminum/Al-alloy is placed in the lower chamber. Before melting it, the furnace chamber is evacuated to create vacuum pressure. The preform in the evacuated upper chamber is simultaneously heated to temperatures of $700-750{ }^{\circ} \mathrm{C}$. Once the thermal equilibrium is attained, pressurized gas is allowed to enter the chambers, which forces the melt into the preform. Finally, the infiltrated sample is furnace cooled to room temperature. The preform and melt temperatures can be independently controlled using this apparatus [116,123,142].

The gas pressure infiltration technique requires a longer processing time, which has been exploited to improve the interfacial bonding between the reinforcement and metal matrix (i.e., copper or aluminum) along with matrix alloying and/or reinforcement coating with carbideforming elements. Mostly copper matrix composites [40-43,46,47,53,60,65,66,84,91,153,154] and AMCs $[118,119,134,139,155]$ reinforced with high-volume fraction of diamond were 
fabricated by this technique. Ruch et al. [102] obtained a higher thermal conductivity with the composite fabricated by the gas pressure infiltration method compared to that fabricated by squeeze casting. Formation of a thin carbide layer at the interface due to the longer exposure time was credited for the higher thermal conductivity of the processed metal.

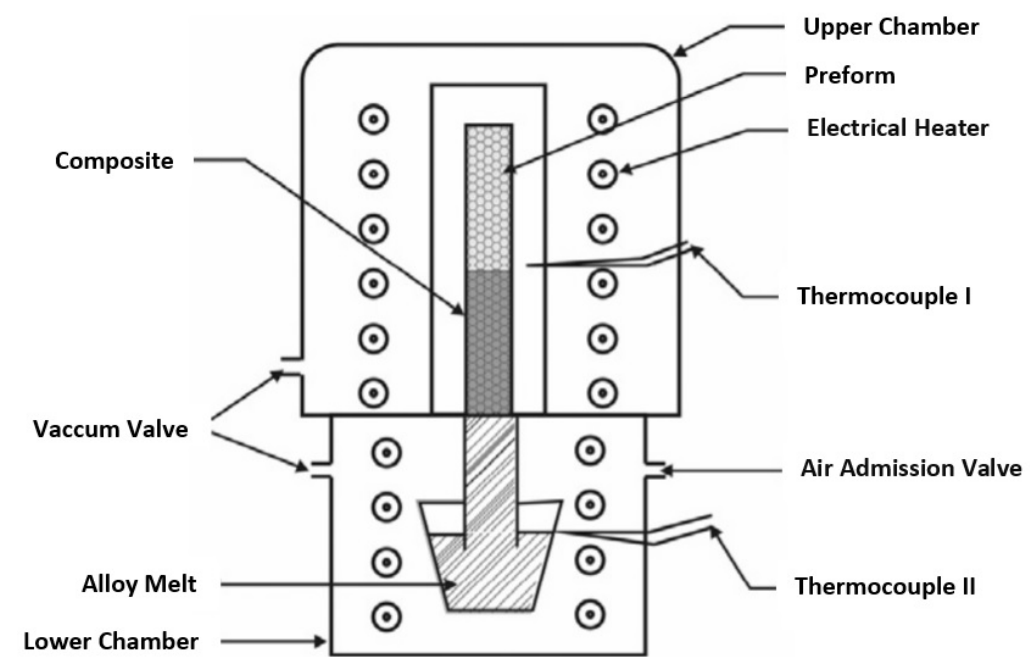

Figure 13. Schematic diagram of the gas pressure infiltration apparatus [142].

The success of the liquid infiltration process (squeeze casting and gas pressure infiltration) depends on the porosity and the strength of the preform. The open pore structure allows the metal or alloys to flow. The strength enables the preform to withstand pressures applied during the infiltration process without becoming deformed $[25,156]$. Since the binder provides strength to the preform, it should be restricted to an optimum amount so that it does not block the pores.

\subsection{Powder Metallurgy}

The powder metallurgy process has emerged as an effective means for synthesizing near net shape composite products. The process not only offers a homogeneous dispersion of reinforcements in the matrix phase but can also prevent undesirable interaction between them $[101,108,157]$. Powder metallurgy involves milling and blending of reinforcements into metal matrix powders. The milled/blended powder mixture is further cold pressed to form a compact, which is subjected to solid state sintering. During sintering, the compact is heated to a temperature below its melting point but high enough to cause diffusion bonding. The developed microstructure determines the thermo-mechanical properties of the composite. The consolidated composite is available to be fabricated into final product through secondary thermo-mechanical processing like rolling, forging, or extrusion $[22,39,73,151]$. Hot press sintering, pulsed electric current sintering (PECS), and microwave sintering were reported to consolidate MMCs fabricated for heat sink applications.

\subsubsection{Hot Press Sintering}

Hot press sintering is the conventional sintering method for MMCs. The copper matrix composites reinforced with carbon fibers (30-40 vol\%) [39], SiC particles (40 vol\%) [77], graphite flakes (38-60\%) [44], Cr-coated graphite fibers (35-50 vol\%) [70], Ti- and Cucoated diamond particles (55 vol\%) [64], and aluminum matrix composites containing $\mathrm{B}_{4} \mathrm{C}(25 \mathrm{vol} \%)$ [105] and graphite flakes (10-90 vol\%) [127] were consolidated by hot press sintering. Besides $\mathrm{CuCr}$ alloy and $\mathrm{Al}$ containing $5-10 \mathrm{vol} \%$, AlSi alloy reinforced with diamond particles (50 vol\%) [44] and carbon fibers (10-50 vol\%) [39,131], respectively, were also consolidated by hot press sintering. In this method, a uniaxial pressure is applied at a high temperature below the melting point [39]. The external heaters are used to heat 
the die and the powder contained in it. The apparently slow heating rate induces grain growth $[57,108]$.

\subsubsection{Pulsed Electric Current Sintering (PECS)}

In this method, the sample is heated by the applied electric field. This process involves simultaneous application of a pulsed direct current and uniaxial pressure on the powder or the compact. The current passing through the die and the compact (if conductive) is transformed into heat by a Joule heating mechanism $[57,62,129,158]$. A faster heating rate, shorter holding time, finer microstructure, and higher densities at lower temperatures are the advantages offered by this technique $[51,57,61,129,158,159]$. Spark plasma sintering (SPS) and the pulse plasma sintering (PPS) are the types of PECs. Even though the existence of plasma in SPS is contentious, it has been the most popular sintering method to consolidate MMCs. Copper matrix composites reinforced with (30-80 vol\%) diamond particles were preferentially consolidated by SPS $[45,54,57,61-63,67,90,92]$. It was also used in the consolidation of $\mathrm{CNT}(0-15 \mathrm{vol} \%)$-reinforced $\mathrm{Cu}$ [74], and $\mathrm{Al}$ [137] matrix composites and in carbon fiber (30 vol\%) [133] and graphite flakes (50 vol\%) [129] reinforced AMCs as well. The pulse plasma sintering (PPS) was used in the sintering of copper matrix composites reinforced with $50 \mathrm{vol} \%$ diamond particles $[50,56,58]$.

\subsubsection{Microwave Sintering}

This is a novel technique of sintering, which generates heat by transforming electromagnetic radiations into heat in the compact being sintered. Microwave sintering offers a high volumetric heating rate, shorter processing time, finer homogenous microstructure, improved mechanical properties, enhanced densification, reduced energy consumption, and environment friendliness over other methods [101,108,157]. Moreover, microwave sintering is cheaper and more productive than spark plasma sintering [160]. Despite all these advantages, microwave sintering has rarely been employed in research investigations involving the fabrication of MMCs intended for heat sink/thermal management application. It was used in the consolidation of $1.5 \mathrm{vol} \% \mathrm{SiC}$ nanoparticle-reinforced AMC [101].

\section{Potential Heat Sink Materials}

The heat sink materials should not only have high thermal conductivities above $300 \mathrm{Wm}^{-1} \mathrm{~K}^{-1}[6,12,22]$, but also have coefficients of thermal expansion matching those of the semiconductor chips and ceramic substrate $[6,7,11,21]$, typically in the range of $3 \times 10^{-6} \mathrm{~K}^{-1}$ to $7 \times 10^{-6} \mathrm{~K}^{-1}[7,11,22]$. Therefore, these limits on the thermal conductivity and coefficient of thermal expansion may be referred to as an acceptable thermal performance. For novel composites to be considered as potential heatsink materials, they must demonstrate an acceptable thermal performance. Figure 14 illustrates a graphical evaluation of the thermal performance of composites in terms of the thermal conductivity and coefficient of thermal expansion. While the two vertical green lines represent the acceptable range of the coefficient of thermal expansion, a horizontal gray line represents the lower limit for the thermal conductivity.

The thermal performance of the composites can be observed to be affected not only by the type of reinforcements, but also by the techniques to improve the interfacial bonding and processing routes. The diamond particles are observed to be the most promising reinforcement in copper matrix when the interfacial bonding was improved. Alloying copper matrix by carbide-forming elements like zirconium [65] or boron [84], and surface metallization of diamond particles by carbide-forming elements like $\mathrm{W}$ [59] or $\mathrm{Mo}_{2} \mathrm{C}$ [53] are observed to be beneficial in improving interfacial bonding. Titanium-coated diamond particle reinforcement in aluminum alloy is observed to demonstrate an acceptable thermal performance [116]. Further, the gas/vacuum pressure infiltration techniques are noted to be prominent in promoting interfacial bonding due to their longer processing time. 
Table 1. Metal matrix composite in Heat Sink Application: Reinforcement, Processing, and Properties.

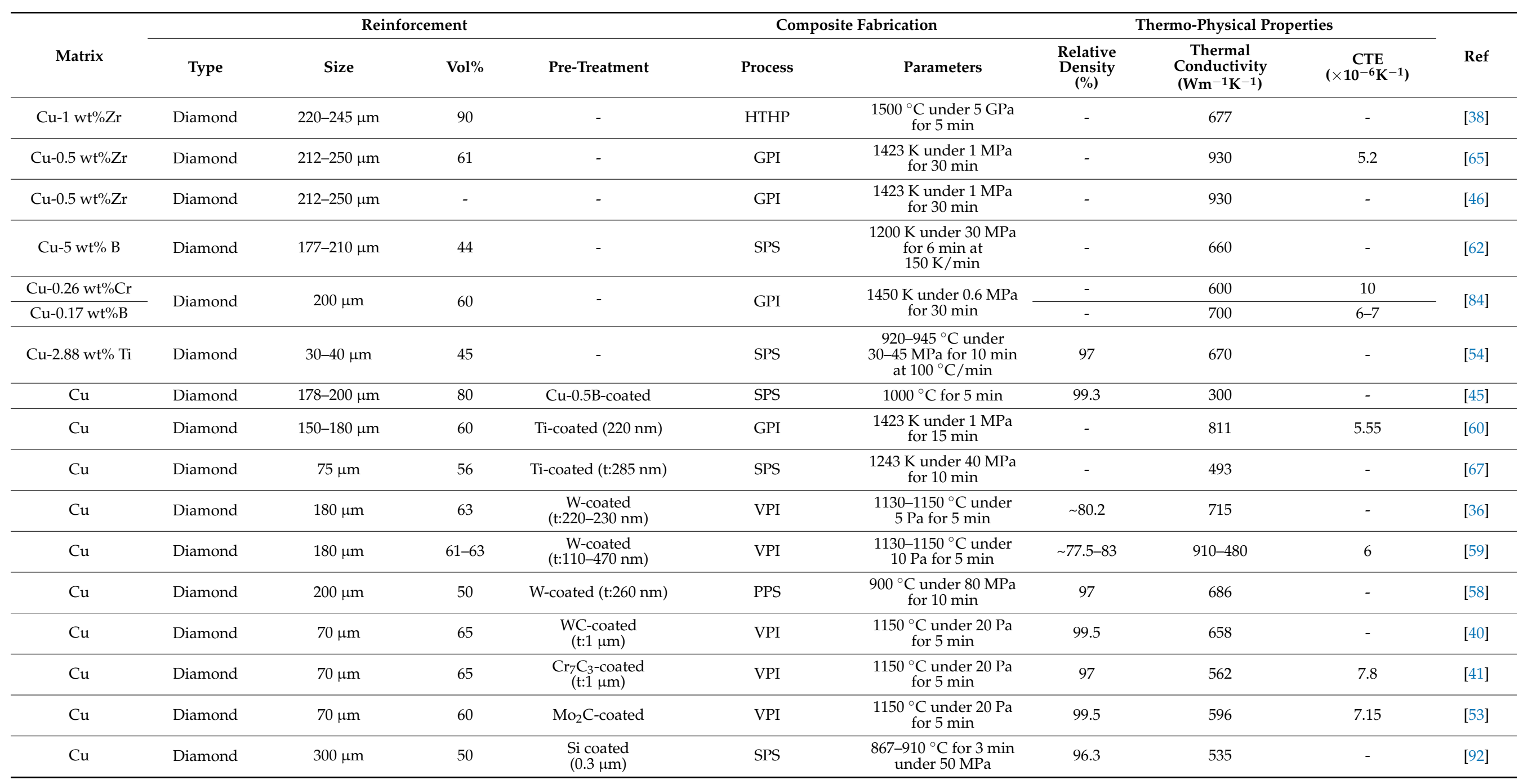


Table 1. Cont.

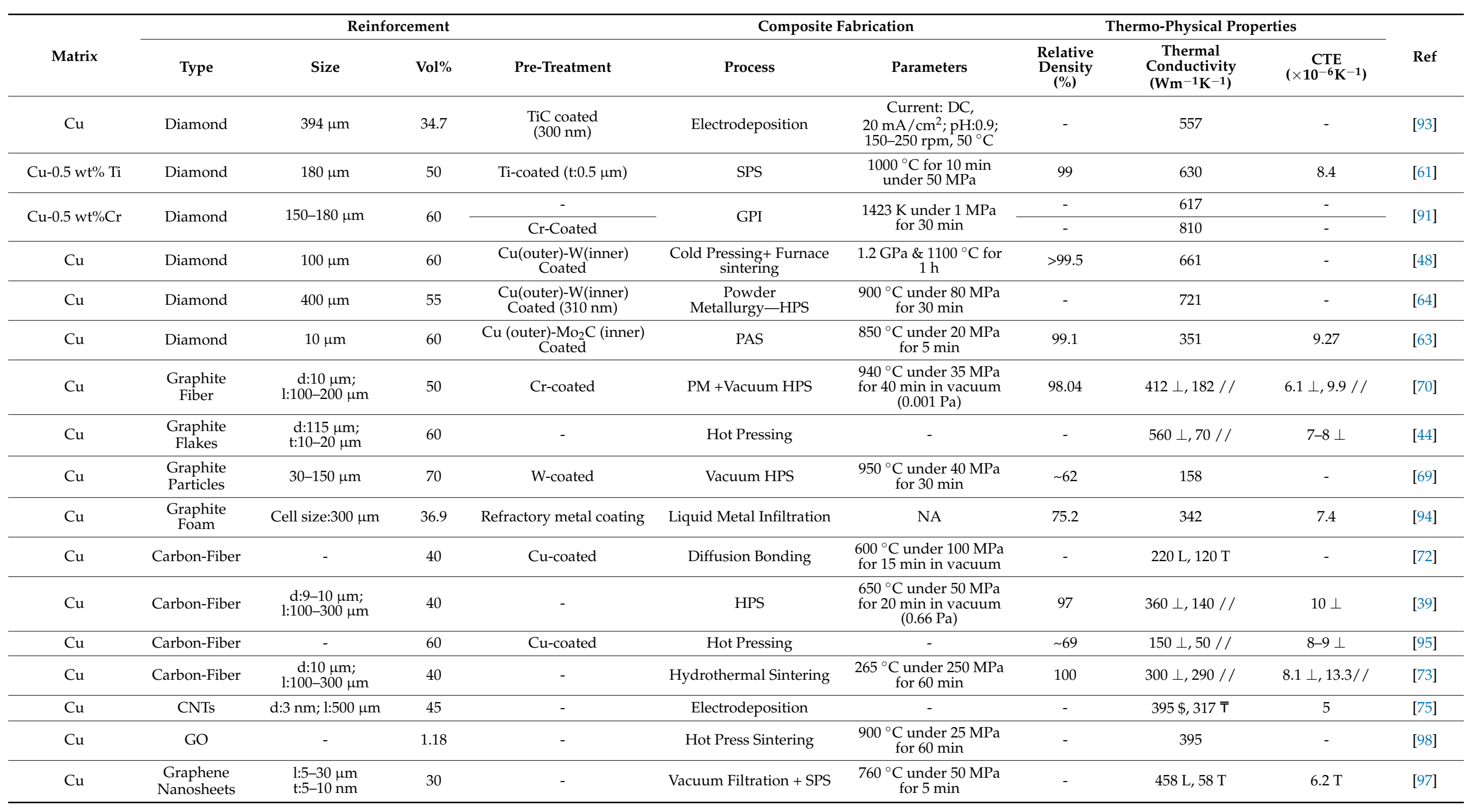


Table 1. Cont.

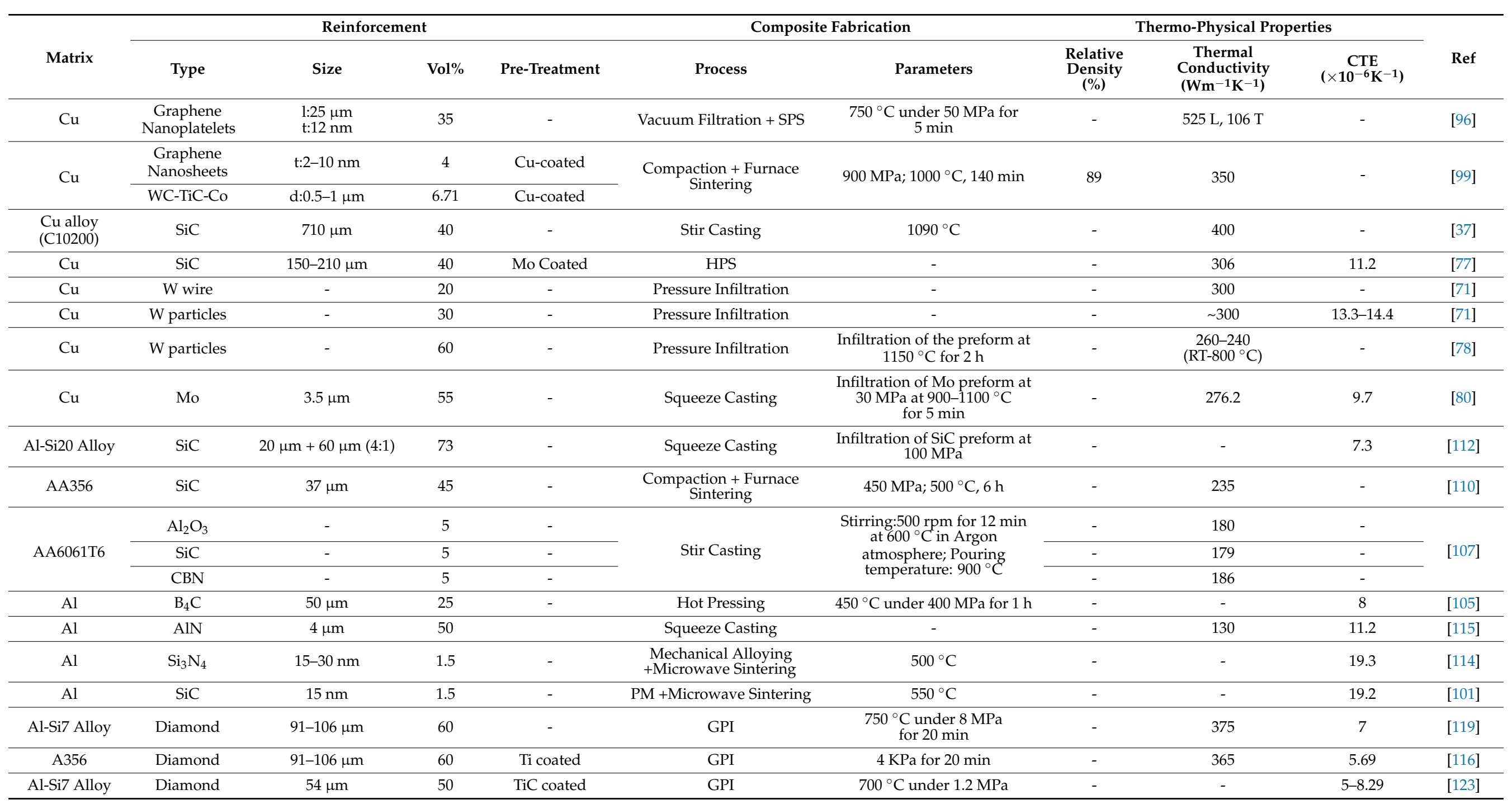


Table 1. Cont.

\begin{tabular}{|c|c|c|c|c|c|c|c|c|c|c|}
\hline \multirow[b]{2}{*}{ Matrix } & \multicolumn{4}{|c|}{ Reinforcement } & \multicolumn{2}{|c|}{ Composite Fabrication } & \multicolumn{3}{|c|}{ Thermo-Physical Properties } & \multirow[b]{2}{*}{ Ref } \\
\hline & Type & Size & Vol\% & Pre-Treatment & Process & Parameters & $\begin{array}{c}\text { Relative } \\
\text { Density } \\
(\%)\end{array}$ & $\begin{array}{l}\text { Thermal } \\
\text { Conductivity } \\
\left(\mathrm{Wm}^{-1} \mathrm{~K}^{-1}\right)\end{array}$ & $\underset{\left(\times 10^{-6} \mathrm{~K}^{-1}\right)}{\mathrm{CTE}}$ & \\
\hline $\mathrm{Al}$ & Diamond & $150-180 \mu \mathrm{m}$ & - & W coated $(45 \mathrm{~nm})$ & GPI & $800^{\circ} \mathrm{C}$ under $1 \mathrm{MPa}$ for $60 \mathrm{~min}$ & - & 620 & - & [124] \\
\hline AlSi7 Alloy & \multirow{2}{*}{ Diamond } & \multirow{2}{*}{$91-106 \mu \mathrm{m}$} & \multirow{2}{*}{$60-65$} & \multirow{2}{*}{-} & \multirow{2}{*}{ GPI } & \multirow{2}{*}{$750^{\circ} \mathrm{C}$ under $8 \mathrm{MPa}$ for $20 \mathrm{~min}$} & - & 375 & - & \multirow{2}{*}{102} \\
\hline $\mathrm{Al}$ & & & & & & & - & 670 & - & \\
\hline \multirow{2}{*}{$\mathrm{Al}$} & \multirow{2}{*}{ Diamond } & \multirow{2}{*}{$395 \mu \mathrm{m}$} & \multirow{2}{*}{62} & \multirow{2}{*}{-} & \multirow{2}{*}{ GPI } & $760^{\circ} \mathrm{C}$ under $0.5 \mathrm{MPa}$ for $15 \mathrm{~min}$ & - & 636 & - & \multirow{2}{*}{125} \\
\hline & & & & & & $850^{\circ} \mathrm{C}$ under $0.5 \mathrm{MPa}$ for $1 \mathrm{~min}$ & - & 676 & - & \\
\hline \multirow{3}{*}{$\mathrm{Al}$} & \multirow{3}{*}{ Diamond } & \multirow{3}{*}{$150-178 \mu \mathrm{m}$} & \multirow{3}{*}{68} & \multirow{3}{*}{-} & \multirow{3}{*}{ GPI } & $750^{\circ} \mathrm{C}$ under $1 \mathrm{MPa}$ for $20 \mathrm{~min}$ & 99.2 & 655 & - & \multirow{3}{*}[126]{} \\
\hline & & & & & & $800^{\circ} \mathrm{C}$ under $0.8 \mathrm{MPa}$ for $20 \mathrm{~min}$ & 99.28 & 760 & - & \\
\hline & & & & & & $850^{\circ} \mathrm{C}$ under $0.5 \mathrm{MPa}$ for $20 \mathrm{~min}$ & 99.35 & 738 & - & \\
\hline \multirow[b]{2}{*}{$\mathrm{Al}$} & \multirow[b]{2}{*}{ Diamond } & \multirow[b]{2}{*}{$90-106 \mu \mathrm{m}$} & \multirow[b]{2}{*}{58} & & Squeeze Casting & $80{ }^{\circ} \mathrm{C}$ under $15 \mathrm{MPa}$ for $15 \mathrm{~min}$ & - & 321 & - & \multirow[b]{2}{*}{ [106] } \\
\hline & & & & - & $\begin{array}{l}\text { Squeeze Casting } \\
\text { (Optimized) }\end{array}$ & $850^{\circ} \mathrm{C}$ under $15 \mathrm{MPa}$ for $90 \mathrm{~min}$ & - & 606 & - & \\
\hline $\mathrm{Al}$ & Diamond & $10-15 \mu \mathrm{m}$ & 4.6 & - & GPI & $800^{\circ} \mathrm{C}$ under $5 \mathrm{MPa}$ for $10 \mathrm{~min}$ & - & 315.7 & - & {$[134]$} \\
\hline $\mathrm{A} 12024$ & Graphite flakes & $\begin{array}{c}\mathrm{d}: 500 \mu \mathrm{m} \\
\mathrm{t}: 10 \mu \mathrm{m}\end{array}$ & 50 & - & SPS & $\begin{array}{c}600^{\circ} \mathrm{C} \text { for } 10 \min \text { under } 45 \text { and } \\
50 \mathrm{MPa}\end{array}$ & - & $390 \mathrm{~L} ; 40 \mathrm{~T}$ & $-7.3 \mathrm{~L} ; 16.3 \mathrm{~T}$ & [129] \\
\hline $\mathrm{Al}$ & Graphite flakes & $1: 550 \mu \mathrm{m} ; \mathrm{t}: 30 \mu \mathrm{m}$ & 50 & - & HPS & $600^{\circ} \mathrm{C}$ under $60 \mathrm{MPa}$ for $30 \mathrm{~min}$ & 97.5 & $400 \mathrm{~L}, 45 \mathrm{~T}$ & $21.8 \mathrm{~L},-10.5 \mathrm{~T}$ & [140] \\
\hline $\mathrm{Al}$ & Graphite flakes & $1: 500 \mu \mathrm{m}$ & 50 & - & $\begin{array}{l}\text { Powder } \\
\text { Metallurgy }\end{array}$ & - & 99.6 & $604 \mathrm{~L}^{\wedge}$ & - & [128] \\
\hline $\mathrm{Al}$ & RGO & - & 3 & - & $\begin{array}{l}\text { Compaction }+ \\
\text { Sintering }\end{array}$ & $\begin{array}{c}200 \mathrm{MPa} \text { and } 600^{\circ} \mathrm{C} \text { for } 5 \mathrm{~h} \\
\text { in Argon }\end{array}$ & 42 & 260 & - & {$[138]$} \\
\hline $\mathrm{Al}-3 \mathrm{wt} \% \mathrm{Mg}$ & Carbon-Fiber & $\mathrm{d}: 10 \mu \mathrm{m}$ & 57.6 & - & GPI & $750^{\circ} \mathrm{C}$ under $5 \mathrm{MPa}$ for $2 \mathrm{~min}$ & - & $540 \mathrm{~L}$ & -1 to $-1.9 \mathrm{~L}$ & [135] \\
\hline $\mathrm{Al}$ & Carbon-Fiber & $\mathrm{d}: 11 \mu \mathrm{m}$ & - & - & $\begin{array}{l}\text { Pressure } \\
\text { Infiltration }\end{array}$ & $\begin{array}{l}1073 \mathrm{~K} \text { under } 0.8 \mathrm{MPa} \text { for } 1 \mathrm{~min} ; \\
\text { cooling-10 min }\end{array}$ & - & $273.2 \mathrm{~L}$ & - & [136] \\
\hline $\begin{array}{l}\mathrm{Al}+(5 \mathrm{Vol} \%) \\
\mathrm{Al}-\mathrm{Si} \text { alloy }\end{array}$ & Carbon-Fiber & $\begin{array}{l}\mathrm{d}: 8 \mu \mathrm{m} \\
\mathrm{l}: 200 \mu \mathrm{m}\end{array}$ & 50 & - & HPS & $600{ }^{\circ} \mathrm{C}$ under $60 \mathrm{MPa}$ for $30 \mathrm{~min}$ & - & $258 \mathrm{~L}$ & $7.09 \mathrm{~L}$ & {$[39]$} \\
\hline $\begin{array}{l}\mathrm{Al}+(5 \mathrm{Vol} \%) \\
\mathrm{Al}-\mathrm{Si} \text { alloy }\end{array}$ & Carbon-Fiber & $\begin{array}{l}\mathrm{d}: 8 \mu \mathrm{m} \\
\mathrm{l}: 200 \mu \mathrm{m}\end{array}$ & 50 & - & Hot Pressing & $600^{\circ} \mathrm{C}$ under $60 \mathrm{MPa}$ for $30 \mathrm{~min}$ & 97 & $258 \mathrm{~L}$ & $7 \mathrm{~L}$ & [131] \\
\hline $\begin{array}{l}\mathrm{Al}+(10 \mathrm{Vol} \%) \\
\mathrm{Al}-\mathrm{Si} \text { alloy }\end{array}$ & Carbon-Fiber & $\begin{array}{l}\mathrm{d}: 10 \mu \mathrm{m} ; \\
\mathrm{l}: 270 \mu \mathrm{m}\end{array}$ & 40 & - & SPS & $\begin{array}{l}873 \mathrm{~K} \text { under } 10 \mathrm{MPa} \text { for } 60 \mathrm{~min} \text { at } \\
20 \mathrm{~K} / \mathrm{min}\end{array}$ & 99.4 & $323 \mathrm{~L}$ & - & [133] \\
\hline AA6063 & Carbon-Fiber & $\begin{array}{l}\mathrm{d}: 10 \mu \mathrm{m} ; \\
\mathrm{l}: 270 \mu \mathrm{m}\end{array}$ & $67.9-70$ & - & $\begin{array}{l}\text { Pressure } \\
\text { Infiltration }\end{array}$ & $900^{\circ} \mathrm{C}$ under $5 \mathrm{MPa}$ for $10 \mathrm{~min}$ & - & $407 \mathrm{~L}$ & $(-0.26$ to +0.26$) \mathrm{L}$ & [132] \\
\hline
\end{tabular}


Table 1. Cont.

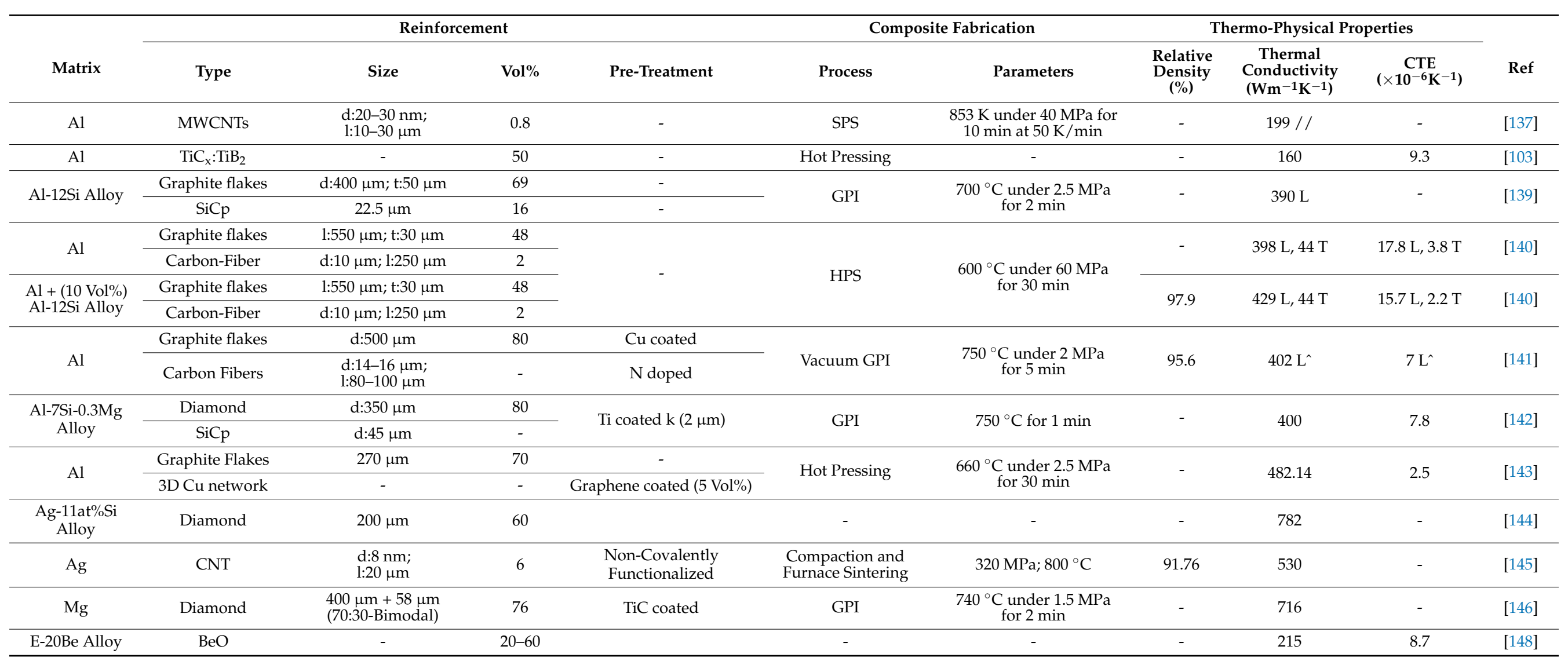

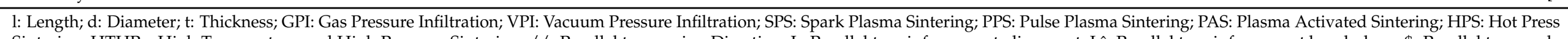

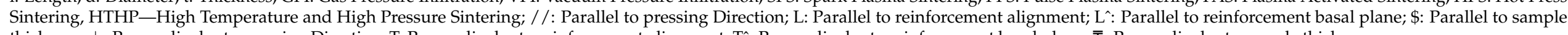
thickness; $\perp$ : Perpendicular to pressing Direction; T: Perpendicular to reinforcement alignment; $T^{\wedge}$ : Perpendicular to reinforcement basal plane; $\bar{T}$ : Perpendicular to sample thickness. 


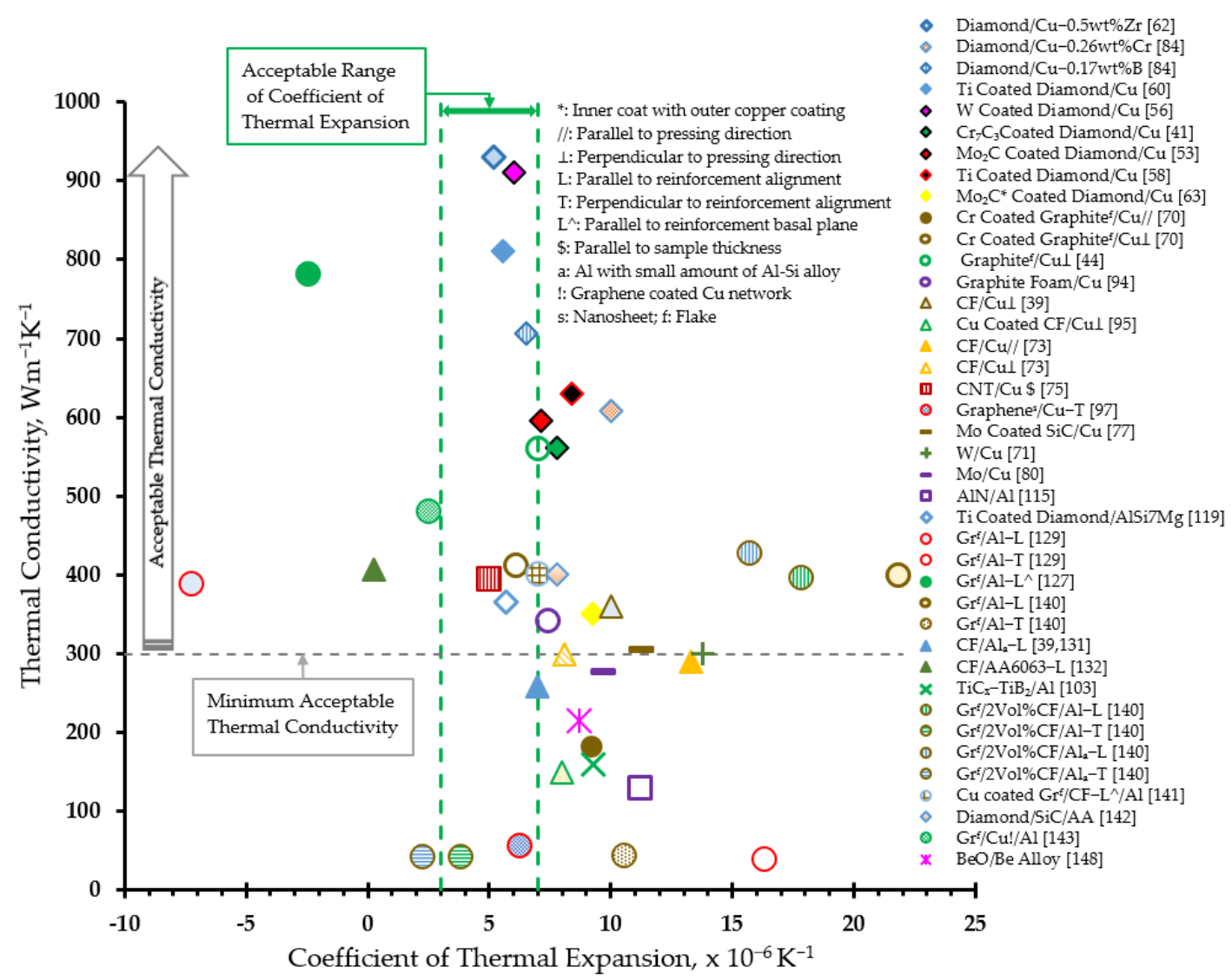

Figure 14. Thermal performance evaluation of metal matrix composites for heat sink applications (see Table 1 for detailed data). (Note: Color of marker outline represents a processing technique as follows: Blue- Gas Pressure Infiltration; BlackVacuum Pressure Infiltration; Olive Green-Pressure Infiltration; Red-Spark Plasma Sintering; Yellow-Plasma Activated Sintering; Brown-Hot Press Sintering; Green-Hot Pressing; Orange-High-Temperature and High-Pressure Sintering; PurpleSqueeze Casting; Maroon-Electro Deposition).

The other carbon-based reinforcements like graphite, carbon fiber, and CNTs are also featured in Figure 14. Such reinforcements are incorporated into the matrix using the powder metallurgy route including hot pressing, hot press sintering, spark plasma sintering, high-temperature and high-pressure sintering, etc. Graphite as reinforcement in copper presents acceptable thermal properties only in the direction perpendicular to the pressing direction $[44,70]$. Graphite reinforcement induced a very large anisotropy in the coefficient of thermal expansion of aluminum, ranging from negative $[127,129]$ to unacceptably high $[129,140]$ values. An acceptable thermal performance is observed by reinforcing CNTs in copper by electrodeposition [75]. Carbon fibers have also been reinforced in copper $[39,73]$ and aluminum $[39,131,132]$ matrices, but the composites did not demonstrate an acceptable thermal performance. Hybridizing composites can be an effective alternative. When gas pressure infiltration was used to fabricate hybrid AMC reinforced with graphite flakes and carbon fibers, an acceptable thermal performance was demonstrated in the direction parallel to the reinforcement basal plane [141]. Graphite flake- and graphene-coated copper network-reinforced hybrid composites also feature acceptably high in-plane thermal conductivity and a coefficient of thermal expansion very close to the acceptable range [143]. Such anisotropy may seem to hinder the application of carbon-based reinforcements, although it could be successfully overcome by designing heatsinks to allow heat flow preferentially in one direction. Alternatively, graphite foam can be used to obtain isotropic properties. Graphite foam-reinforced composite is observed 
to demonstrate acceptable thermal conductivity and a coefficient of thermal expansion very close to the acceptable range [94].

AMCs with acceptable $[122,141]$ and/or close to acceptable $[142,143]$ thermal performances (see Figure 14) possess very high specific thermal conductivity in comparison to copper matrix composites with similar thermal performances. The outstanding specific thermal conductivity stems from the lower density of AMCs. This feature makes them most attractive as heat sink composites in portable electronic devices. Additionally, the AMCs containing cheaper reinforcements [141,143] offer an economical option than those containing diamond as reinforcement [122,142].

The incorporation of metal particles like Mo [80] and $\mathrm{W}$ [71] in copper; ceramic particles like AlN [115] and TiC [103] in aluminum; and $\mathrm{BeO}$ in beryllium [148] did not demonstrate an acceptable thermal performance.

\section{Conclusions}

MMCs as heat sink materials were reviewed in this paper. The heat sink materials should demonstrate an acceptable thermal performance, i.e., thermal conductivities above $300 \mathrm{Wm}^{-1} \mathrm{~K}^{-1}$ and coefficients of thermal expansion typically in the range of $3 \times 10^{-6} \mathrm{~K}^{-1}$ to $7 \times 10^{-6} \mathrm{~K}^{-1}$. The current review summarizes the efforts of different researchers in enhancing the thermal performance of metal matrix using a combination of several types of reinforcements to produce composites. Based upon this extensive literature review, the main findings can be summarized as the following:

1. Copper and aluminum are the most commonly used matrix materials for heat sink composites. Diamond particles were observed to be the most promising reinforcement when the interfacial bonding was improved either by alloying matrix or by surface metallization of diamond particles by a carbide-forming element.

2. Another important technique to improve interfacial bonding and thereby the thermal properties in $\mathrm{Al} /$ diamond composites is to promote the formation of an $\mathrm{Al}-\mathrm{C}$ diffusion layer. The formation of a diffusion layer precedes the precipitation of a brittle, hydrophilic interfacial phase of $\mathrm{Al}_{4} \mathrm{C}_{3}$ that serves as a thermal barrier.

3. The MMCs with other lone carbon-based reinforcements like graphite, carbon fiber, $\mathrm{CNTs}$, and graphene are generally reported to demonstrate unacceptable and anisotropic thermal performances.

4. A trend setting approach was noticed when a diamond film was coated on another reinforcement in the fabrication of AMCs. A significantly high ratio of thermal conductivity to diamond loading was observed with merely a small volume percentage of diamond. This technique needs to be further explored to establish the feasibility of this technique in providing MMCs with an acceptable thermal performance. This technique may not only reduce diamond loading but also reduce the overall cost.

5. Using graphite foam or metallic foam coated with carbon-based reinforcements is another step towards obtaining MMCs with isotropic properties. Further, it can provide an effective heat transfer path for better heat conduction.

6. The AMCs with acceptable and/or close to acceptable thermal performances possess a very high specific thermal conductivity, which makes them more attractive for heat sink applications in portable electronic devices.

7. Among the liquid state processing techniques, the gas pressure infiltration technique has emerged as being effective. This technique offers control over the infiltration temperature, pressure, and reinforcement-matrix melt contact time. This feature can be exploited to improve the interfacial bonding between the reinforcement and the matrix material.

8. The SPS and hot press sintering has emerged to be the most common sintering methods when the powder metallurgy route is adopted for the fabrication of MMCs. Though microwave sintering is hailed to offer significant advantages over other methods, it has rarely been used, and it needs to be further explored. 
9. In view of the above findings, it can be concluded that the thermal performance of the composites is affected not only by the type of reinforcements, but also by the techniques to improve the interfacial bonding and processing routes. The novel techniques should be further explored to meet the ever-increasing thermal management challenges.

Author Contributions: Conceptualization, S.F.H.; methodology, M.M.A.B.; formal analysis, S.F.H. and M.M.A.B.; investigation, S.F.H. and M.M.A.B.; resources, N.S. and F.P.; data curation, S.F.H., N.S. and F.P.; writing-M.M.A.B.; writing—review and editing, S.F.H. and N.S.; supervision, S.F.H.; project administration, S.F.H.; funding acquisition, S.F.H. All authors have read and agreed to the published version of the manuscript.

Funding: The authors would like to acknowledge the support provided by the Deanship of Scientific Research (DSR) at King Fahd University of Petroleum and Minerals (KFUPM) for funding this work through project No. DF181014.

Institutional Review Board Statement: Not applicable.

Informed Consent Statement: Not applicable.

Conflicts of Interest: The authors declare no conflict of interest.

\section{References}

1. Khattak, Z.; Ali, H.M. Air cooled heat sink geometries subjected to forced flow: A critical review. Int. J. Heat Mass Transf. 2019, 130, 141-161. [CrossRef]

2. Chingulpitak, S.; Wongwises, S. A review of the effect of flow directions and behaviors on the thermal performance of conventional heat sinks. Int. J. Heat Mass Transf. 2015, 81, 10-18. [CrossRef]

3. Ahmed, H.E.; Salman, B.H.; Kherbeet, A.S.; Ahmed, M.I. Optimization of thermal design of heat sinks: A review. Int. J. Heat Mass Transf. 2018, 118, 129-153. [CrossRef]

4. Pawar, S.P.; Ghuge, N.C.; Palande, D.D. Review-Design and Analysis of Heat Sink Optimization and its Comparison with Commercially Available Heat Sink. Int. J. Appl. Innov. Eng. Manag. 2015, 4, 101-104. [CrossRef]

5. Martinez-Maradiaga, D.; Damonte, A.; Manzo, A.; Haertel, J.H.; Engelbrecht, K. Design and testing of topology optimized heat sinks for a tablet. Int. J. Heat Mass Transf. 2019, 142, 118429. [CrossRef]

6. Miranda, A.; Barekar, N.; McKay, B.J. MWCNTs and their use in Al-MMCs for ultra-high thermal conductivity applications: A review. J. Alloy. Compd. 2019, 774, 820-840. [CrossRef]

7. Zweben, C. Advances in composite materials for thermal management in electronic packaging. JOM 1998, 50, 47-51. [CrossRef]

8. Tong, H.M. Microelectronics packaging: Present and future. Mater. Chem. Phys. 1995, 40, 147-161. [CrossRef]

9. Bogatin, E. High Performane Packaging Solutions; Integrated Circuit Engineering Corporation: Scottsdale, AZ, USA, 1991.

10. Gong, L.; Li, Y.; Bai, Z.; Xu, M. Thermal performance of micro-channel heat sink with metallic porous/solid compound fin design. Appl. Therm. Eng. 2018, 137, 288-295. [CrossRef]

11. Neubauer, E.; Angerer, P.; Korb, G. Heat sink materials with tailored properties for thermal management. In Proceedings of the 28th International Spring Seminar on Electronics Technology Meeting the Challenges of Electronics Technology Progress, 2005, Wiener Neustadt, Austria, 19-20 May 2005. [CrossRef]

12. Occhionero, M.A.; Adams, R.W. AlSiC, and AlSiC hybrid composites for flip chips, optoelectronics, power, and high brightness LED thermal management solutions. In Proceedings of the 2005 6th International Conference on Electronic Packaging Technology, Shenzhen, China, 30 August-2 September 2005. [CrossRef]

13. Razeeb, K.M.; Dalton, E.; Cross, G.L.W.; Robinson, A.J. Present and future thermal interface materials for electronic devices. Int. Mater. Rev. 2018, 63, 1-21. [CrossRef]

14. Smoyer, J.L.; Norris, P.M. Brief Historical Perspective in Thermal Management and the Shift Toward Management at the Nanoscale. Heat Transf. Eng. 2019, 40, 269-282. [CrossRef]

15. Shen, Y.L.; Needleman, A.; Suresh, S. Coefficients of thermal expansion of metal-matrix composites for electronic packaging. Metall. Mater. Trans. A 1994, 25, 839-850. [CrossRef]

16. Pop, E.; Sinha, S.; Goodson, K.E. Heat generation and transport in nanometer-scale transistors. Proc. IEEE 2006, 94, 1587-1601. [CrossRef]

17. Garimella, S.V.; Fleischer, A.S.; Murthy, J.Y.; Keshavarzi, A.; Prasher, R.; Patel, C.; Bhavnani, S.H.; Venkatasubramanian, R.; Mahajan, R.; Joshi, Y.; et al. Thermal challenges in next-generation electronic systems. IEEE Trans. Compon. Packag. Technol. 2008, 31, 801-815. [CrossRef]

18. Hansson, J.; Nilsson, T.M.J.; Ye, L.; Liu, J. Novel nanostructured thermal interface materials: A review. Int. Mater. Rev. 2018, 63, 22-45. [CrossRef] 
19. Pedram, M.; Nazarian, S. Thermal modeling, analysis, and management in VLSI circuits: Principles and methods. Proc. IEEE 2006, 94, 1487-1501. [CrossRef]

20. Reda, S.; Cochran, R.; Nowroz, A.N. Improved thermal tracking for processors using hard and soft sensor allocation techniques. IEEE Trans. Comput. 2011, 60, 841-851. [CrossRef]

21. Wei, J. Challenges in cooling design of CPU packages for high-performance servers. Heat Transf. Eng. 2008, 29, 178-187. [CrossRef]

22. Mallik, S.; Ekere, N.; Best, C.; Bhatti, R. Investigation of thermal management materials for automotive electronic control units. Appl. Therm. Eng. 2011, 31, 355-362. [CrossRef]

23. Abbas, A.; Wang, C.C. Augmentation of natural convection heat sink via using displacement design. Int. J. Heat Mass Transf. 2020, 154, 119757. [CrossRef]

24. Choi, J.; Jeong, M. Compact, lightweight, and highly efficient circular heat sink design for high-end PCs. Appl. Therm. Eng. 2016, 92, 162-171. [CrossRef]

25. Chung, D.D.L. Materials for thermal conduction. Appl. Therm. Eng. 2001, 21, 1593-1605. [CrossRef]

26. Tjong, S.C.; Ma, Z.Y. Microstructural and mechanical characteristics of in situ metal matrix composites. Mater. Sci. Eng. 2000, 29, 49-113. [CrossRef]

27. Tham, L.M.; Gupta, M.; Cheng, L. Influence of processing parameters on the near-net shape synthesis of aluminium-based metal matrix composites. J. Mater. Process. Technol. 1999, 89-90, 128-134. [CrossRef]

28. Han, X.H.; Wang, Q.; Park, Y.G.; T'Joen, C.; Sommers, A.; Jacobi, A. A review of metal foam and metal matrix composites for heat exchangers and heat sinks. Heat Transf. Eng. 2012, 33, 991-1009. [CrossRef]

29. Rawal, S. Metal-matrix composites for space applications. JOM 2001, 53, 14-17. [CrossRef]

30. Rao, V.; Murthy, M.K.; Nagaraju, J. Thermal conductivity and thermal contact conductance studies on $\mathrm{Al}_{2} \mathrm{O}_{3} / \mathrm{Al}_{-} \mathrm{AlN} \mathrm{metal}$ matrix composite. Compos. Sci. Technol. 2004, 64, 2459-2462. [CrossRef]

31. Miracle, D.B. Metal matrix composites-From science to technological significance. Compos. Sci. Technol. 2005, 65, 2526-2540. [CrossRef]

32. Rosso, M. Ceramic and metal matrix composites: Routes and properties. J. Mater. Process. Technol. 2006, 175, 364-375. [CrossRef]

33. Schöbel, M.; Altendorfer, W.; Degischer, H.; Vaucher, S.; Buslaps, T.; Di Michiel, M.; Hofmann, M. Internal stresses and voids in $\mathrm{SiC}$ particle reinforced aluminum composites for heat sink applications. Compos. Sci. Technol. 2011, 71, 724-733. [CrossRef]

34. Sidhu, S.S.; Kumar, S.; Batish, A. Metal Matrix Composites for Thermal Management: A Review. Crit. Rev. Solid State Mater. Sci. 2016, 41, 132-157. [CrossRef]

35. Qu, X.H.; Zhang, L.; Wu, M.; Ren, S. Bin Review of metal matrix composites with high thermal conductivity for thermal management applications. Prog. Nat. Sci. Mater. Int. 2011, 21, 189-197. [CrossRef]

36. Abyzov, A.M.; Shakhov, F.M.; Averkin, A.I.; Nikolaev, V.I. Mechanical properties of a diamond-copper composite with high thermal conductivity. Mater. Des. 2015, 87, 527-539. [CrossRef]

37. Fatoba, O.S.; Popoola, O.; Popoola, A.P.I. The Effects of Silicon Carbide Reinforcement on the Properties of Cu/SiCp Composites. Silicon 2015, 7, 351-356. [CrossRef]

38. He, J.; Wang, X.; Zhang, Y.; Zhao, Y.; Zhang, H. Thermal conductivity of Cu-Zr/diamond composites produced by high temperature-high pressure method. Compos. Part B Eng. 2015, 68, 22-26. [CrossRef]

39. Silvain, J.F.; Veillère, A.; Lu, Y. Copper-carbon and aluminum-carbon composites fabricated by powder metallurgy processes. J. Phys. Conf. Ser. 2014, 525. [CrossRef]

40. Kang, Q.; He, X.; Ren, S.; Liu, T.; Liu, Q.; Wu, M.; Qu, X. Microstructure and thermal properties of copper-diamond composites with tungsten carbide coating on diamond particles. Mater. Charact. 2015, 105, 18-23. [CrossRef]

41. Kang, Q.; He, X.; Ren, S.; Zhang, L.; Wu, M.; Guo, C.; Cui, W.; Qu, X. Preparation of copper-diamond composites with chromium carbide coatings on diamond particles for heat sink applications. Appl. Therm. Eng. 2013, 60, 423-429. [CrossRef]

42. Tejado, E.; Müller, A.V.; You, J.H.; Pastor, J.Y. The thermo-mechanical behaviour of W-Cu metal matrix composites for fusion heat sink applications: The influence of the Cu content. J. Nucl. Mater. 2018, 498, 468-475. [CrossRef]

43. Tejado, E.; Müller, A.V.; You, J.H.; Pastor, J.Y. Evolution of mechanical performance with temperature of W/Cu and W/CuCrZr composites for fusion heat sink applications. Mater. Sci. Eng. A 2018, 712, 738-746. [CrossRef]

44. Schubert, T.; Weidmüller, H.; Weißgärber, T.; Kieback, B. Carbide formation in copper-carbon composites and its effect on thermal conductivity. In Advances in Powder Metallurgy \& Particulate Materials, Proceedings of the 2007 International Conference on Powder Metallurgy \& Particulate Materials, PowderMet; Metal Powder Industries Federation: Denver, CO, USA, 2007; pp. 910-918.

45. Xia, Y.; Song, Y.-Q.; Lin, C.-G.; Cui, S.; Fang, Z.-Z. Effect of carbide formers on microstructure and thermal conductivity of diamond-Cu composites for heat sink materials. Trans. Nonferrous Met. Soc. China 2009, 19, 1161-1166. [CrossRef]

46. Wang, L.; Li, J.; Bai, G.; Li, N.; Wang, X.; Zhang, H.; Wang, J.; Kim, M.J. Interfacial structure evolution and thermal conductivity of $\mathrm{Cu}-\mathrm{Zr}$ /diamond composites prepared by gas pressure infiltration. J. Alloy. Compd. 2019, 781, 800-809. [CrossRef]

47. Xie, Z.; Guo, H.; Zhang, Z.; Zhang, X. Thermal expansion behaviour and dimensional stability of Diamond/Cu composites with different diamond content. J. Alloy. Compd. 2019, 797, 122-130. [CrossRef]

48. Pan, Y.; He, X.; Ren, S.; Wu, M.; Qu, X. Optimized thermal conductivity of diamond/Cu composite prepared with tungstencopper-coated diamond particles by vacuum sintering technique. Vacuum 2018, 153, 74-81. [CrossRef] 
49. Chang, G.; Sun, F.; Wang, L.; Che, Z.; Wang, X.; Wang, J.; Kim, M.J.; Zhang, H. Regulated Interfacial Thermal Conductance between $\mathrm{Cu}$ and Diamond by a TiC Interlayer for Thermal Management Applications. ACS Appl. Mater. Interfaces 2019, 11, 26507-26517. [CrossRef]

50. Ciupiński, Ł.; Kruszewski, M.J.; Grzonka, J.; Chmielewski, M.; Zielińsk, R.; Moszczyńska, D.; Michalski, A. Design of interfacial $\mathrm{Cr} 3 \mathrm{C} 2$ carbide layer via optimization of sintering parameters used to fabricate copper/diamond composites for thermal management applications. Mater. Des. 2017, 120, 170-185. [CrossRef]

51. Wu, Y.; Luo, J.; Wang, Y.; Wang, G.; Wang, H.; Yang, Z.; Ding, G. Critical effect and enhanced thermal conductivity of Cu-diamond composites reinforced with various diamond prepared by composite electroplating. Ceram. Int. 2019, 45, 13225-13234. [CrossRef]

52. Grech, D.F.; Abela, S.; Attard, M.; Sinagra, E. Coating of diamond particles for production of metal matrix composites. Surf. Eng. 2013, 29, 244-246. [CrossRef]

53. Kang, Q.; He, X.; Ren, S.; Zhang, L.; Wu, M.; Guo, C.; Liu, Q.; Liu, T.; Qu, X. Effect of molybdenum carbide intermediate layers on thermal properties of copper-diamond composites. J. Alloy. Compd. 2013, 576, 380-385. [CrossRef]

54. Che, Q.L.; Chen, X.K.; Ji, Y.Q.; Li, Y.W.; Wang, L.X.; Cao, S.Z.; Jiang, Y.G.; Wang, Z. The influence of minor titanium addition on thermal properties of diamond/copper composites via in situ reactive sintering. Mater. Sci. Semicond. Process. 2015, 30, 104-111. [CrossRef]

55. Cho, H.J.; Yan, D.; Tam, J.; Erb, U. Effects of diamond particle size on the formation of copper matrix and the thermal transport properties in electrodeposited copper-diamond composite materials. J. Alloy. Compd. 2019, 791, 1128-1137. [CrossRef]

56. Rosinski, M.; Ciupinski, L.; Grzonka, J.; Michalski, A.; Kurzydlowski, K.J. Synthesis and characterization of the diamond/copper composites produced by the pulse plasma sintering (PPS) method. Diam. Relat. Mater. 2012, 27-28, 29-35. [CrossRef]

57. Nunes, D.; Correia, J.B.; Carvalho, P.A.; Shohoji, N.; Fernandes, H.; Silva, C.; Alves, L.C.; Hanada, K.; Ösawa, E. Production of $\mathrm{Cu}$ /diamond composites for first-wall heat sinks. Fusion Eng. Des. 2011, 86, 2589-2592. [CrossRef]

58. Abyzov, A.M.; Kruszewski, M.J.; Ciupiński, Ł.; Mazurkiewicz, M.; Michalski, A.; Kurzydłowski, K.J. Diamond-tungsten based coating-copper composites with high thermal conductivity produced by Pulse Plasma Sintering. Mater. Des. 2015, 76, 97-109. [CrossRef]

59. Abyzov, A.M.; Kidalov, S.V.; Shakhov, F.M. High thermal conductivity composite of diamond particles with tungsten coating in a copper matrix for heat sink application. Appl. Therm. Eng. 2012, 48, 72-80. [CrossRef]

60. Wang, L.; Li, J.; Catalano, M.; Bai, G.; Li, N.; Dai, J.; Wang, X.; Zhang, H.; Wang, J.; Kim, M.J. Enhanced thermal conductivity in $\mathrm{Cu}$ /diamond composites by tailoring the thickness of interfacial TiC layer. Compos. Part A Appl. Sci. Manuf. 2018, 113, 76-82. [CrossRef]

61. Che, Q.L.; Zhang, J.J.; Chen, X.K.; Ji, Y.Q.; Li, Y.W.; Wang, L.X.; Cao, S.Z.; Guo, L.; Wang, Z.; Wang, S.W.; et al. Spark plasma sintering of titanium-coated diamond and copper-titanium powder to enhance thermal conductivity of diamond/copper composites. Mater. Sci. Semicond. Process. 2015, 33, 67-75. [CrossRef]

62. Bai, H.; Maa, N.; Lang, J.; Zhu, C. Effect of a new pretreatment on the microstructure and thermal conductivity of Cu/diamond composites. J. Alloy. Compd. 2013, 580, 382-385. [CrossRef]

63. Liu, R.; Luo, G.; Li, Y.; Zhang, J.; Shen, Q.; Zhang, L. Microstructure and thermal properties of diamond/copper composites with Mo 2 C in-situ nano-coating. Surf. Coat. Technol. 2019, 360, 376-381. [CrossRef]

64. Zhang, C.; Wang, R.; Cai, Z.; Peng, C.; Feng, Y.; Zhang, L. Effects of dual-layer coatings on microstructure and thermal conductivity of diamond/Cu composites prepared by vacuum hot pressing. Surf. Coat. Technol. 2015, 277, 299-307. [CrossRef]

65. Li, J.; Wang, X.; Qiao, Y.; Zhang, Y.; He, Z.; Zhang, H. High thermal conductivity through interfacial layer optimization in diamond particles dispersed Zr-alloyed Cu matrix composites. Scr. Mater. 2015, 109, 72-75. [CrossRef]

66. Zhang, X.; Guo, H.; Yin, F.; Fan, Y.; Zhang, Y. Interfacial microstructure and properties of diamond/Cu-xCr composites for electronic packaging applications. Rare Met. 2011, 30, 94-98. [CrossRef]

67. Zhang, Y.; Zhang, H.L.; Wu, J.H.; Wang, X.T. Enhanced thermal conductivity in copper matrix composites reinforced with titanium-coated diamond particles. Scr. Mater. 2011, 65, 1097-1100. [CrossRef]

68. Lambert, M.A.; Fletcher, L.S. Thermal conductivity of graphite/aluminum and graphite/copper composites. J. Heat Transfer 1996, 118, 478-510. [CrossRef]

69. Yang, W.; Zhou, L.; Peng, K.; Zhu, J.; Wan, L. Effect of tungsten addition on thermal conductivity of graphite/copper composites. Compos. Part B Eng. 2013, 55, 1-4. [CrossRef]

70. Zhang, H.; Chao, M.; Zhang, H.; Tang, A.; Ren, B.; He, X. Microstructure and thermal properties of copper matrix composites reinforced by chromium-coated discontinuous graphite fibers. Appl. Therm. Eng. 2014, 73, 739-744. [CrossRef]

71. You, J.H. Copper matrix composites as heat sink materials for water-cooled divertor target. Nucl. Mater. Energy 2015, 5, 7-18. [CrossRef]

72. Koráb, J.; Štefánik, P.; Kavecký, Š.; Šebo, P.; Korb, G. Thermal conductivity of unidirectional copper matrix carbon fibre composites. Compos. Part A Appl. Sci. Manuf. 2002, 33, 577-581. [CrossRef]

73. Prakasam, M.; Morvan, A.; Azina, C.; Constantin, L.; Goglio, G.; Largeteau, A.; Bordère, S.; Heintz, J.M.; Lu, Y.; Silvain, J.F. Ultra-low temperature fabrication of copper carbon fibre composites by hydrothermal sintering for heat sinks with enhanced thermal efficiency. Compos. Part A Appl. Sci. Manuf. 2020, 133. [CrossRef]

74. Chu, K.; Wu, Q.; Jia, C.; Liang, X.; Nie, J.; Tian, W.; Gai, G.; Guo, H. Fabrication and effective thermal conductivity of multi-walled carbon nanotubes reinforced Cu matrix composites for heat sink applications. Compos. Sci. Technol. 2010, 70, 298-304. [CrossRef] 
75. Subramaniam, C.; Yasuda, Y.; Takeya, S.; Ata, S.; Nishizawa, A.; Futaba, D.; Yamada, T.; Hata, K. Carbon nanotube-copper exhibiting metal-like thermal conductivity and silicon-like thermal expansion for efficient cooling of electronics. Nanoscale 2014, 6 , 2669-2674. [CrossRef]

76. Köck, T.; Brendel, A.; Bolt, H. Interface reactions between silicon carbide and interlayers in silicon carbide-copper metal-matrix composites. J. Nucl. Mater. 2007, 362, 197-201. [CrossRef]

77. Schubert, T.; Brendel, A.; Schmid, K.; Koeck, T.; Ciupiński, Ł.; Zieliński, W.; Weißgärber, T.; Kieback, B. Interfacial design of $\mathrm{Cu} / \mathrm{SiC}$ composites prepared by powder metallurgy for heat sink applications. Compos. Part A Appl. Sci. Manuf. 2007, 38, 2398-2403. [CrossRef]

78. Muller, A.V.; Ewert, D.; Galatanu, A.; Milwich, M.; Neu, R.; Pastor, J.Y.; Siefken, U.; Tejado, E.; You, J.H. Melt infiltrated tungsten-copper composites as advanced heat sink materials for plasma facing components of future nuclear fusion devices. Fusion Eng. Des. 2017, 124, 455-459. [CrossRef]

79. Sampath, A.; Ravi, B.G.; Nguyen, H.; Sudarshan, T.S. Enhancing thermal properties of W/Cu composites. Powder Metall. 2001, 44, 313-316. [CrossRef]

80. Chen, G.; Wu, G.; Zhu, D.; Zhang, Q. The Thermo-Physical Properties of High Dense Mo/Cu Composites Fabricated by Squeeze Casting Technology. In Proceedings of the 2005 6th International Conference on Electronic Packaging Technology, Schenzen, China, 30 August-2 September 2005; pp. 321-324. [CrossRef]

81. Das, S.; Das, S.; Das, K. Synthesis and thermal behavior of Cu/Y2W3O 12 composite. Ceram. Int. 2014, 40, 6465-6472. [CrossRef]

82. Sinha, V.; Spowart, J.E. Influence of interfacial carbide layer characteristics on thermal properties of copper-diamond composites. J. Mater. Sci. 2013, 48, 1330-1341. [CrossRef]

83. Clyne, T.W.; Withers, P.J. An Introduction to Metal Matrix Composites; Cambridge University Press: Cambridge, UK, 1993.

84. Weber, L.; Tavangar, R. On the influence of active element content on the thermal conductivity and thermal expansion of Cu-X (X = Cr, B) diamond composites. Scr. Mater. 2007, 57, 988-991. [CrossRef]

85. Chu, K.; Jia, C.; Guo, H.; Li, W. Microstructure and thermal conductivity of Cu-B/diamond composites. J. Compos. Mater. 2013, 47, 2945-2953. [CrossRef]

86. Kidalov, S.V.; Shakhov, F.M. Thermal conductivity of diamond composites. Materials 2009, 2, 2467-2495. [CrossRef]

87. Scott, P.M.; Nicholas, M.; Dewar, B. The wetting and bonding of diamonds by copper-base binary alloys. J. Mater. Sci. 1975, 10, 1833-1840. [CrossRef]

88. Zhu, C.; Zhu, X.; Zhao, H.; Fa, W.; Yang, X.; Zheng, Z. Thermal physical properties of Al-coated diamond/Cu composites. J. Wuhan Univ. Technol. Sci. Ed. 2015, 30, 315-319. [CrossRef]

89. $\mathrm{Hu}, \mathrm{H}$; Kong, J. Improved thermal performance of diamond-copper composites with boron carbide coating. J. Mater. Eng. Perform. 2014, 23, 651-657. [CrossRef]

90. Cui, W.; Xu, H.; Chen, J.-H.; Ren, S.-B.; He, X.-B.; Qu, X.-H. Effect of sintering on the relative density of Cr-coated diamond/Cu composites prepared by spark plasma sintering. Int. J. Miner. Met. Mater. 2016, 23, 716-722. [CrossRef]

91. Wang, L.; Li, J.; Che, Z.; Wang, X.; Zhang, H.; Wang, J.; Kim, M.J. Combining Cr pre-coating and Cr alloying to improve the thermal conductivity of diamond particles reinforced Cu matrix composites. J. Alloy. Compd. 2018, 749, 1098-1105. [CrossRef]

92. Zhu, C.; Wang, C.; Lang, J.; Ma, Y.; Ma, N. Si-coated diamond particles reinforced copper composites fabricated by spark plasma sintering process. Mater. Manuf. Process. 2013, 28, 143-147. [CrossRef]

93. Cho, H.J.; Kim, Y.J.; Erb, U. Thermal conductivity of copper-diamond composite materials produced by electrodeposition and the effect of TiC coatings on diamond particles. Compos. Part B Eng. 2018, 155, 197-203. [CrossRef]

94. Vrable, D.L.; Gottschlich, J.M. Graphite foam/copper composite substrate for electronic cooling. In Proceedings of the Collection of Technical Papers-4th International Energy Conversion Engineering Conference, San Diego, CA, USA, 18 June 2006; pp. 593-602.

95. Korab, J.; Korb, G.; Sebo, P. Thermal expansion and thermal conductivity of continuous carbon fibre reinforced copper matrix composites. Proc. IEEE/CPMT Int. Electron. Manuf. Technol. Symp. 1998, 104-108. [CrossRef]

96. Chu, K.; Wang, X.-H.; Wang, F.; Li, Y.-B.; Huang, D.-J.; Liu, H.; Ma, W.-L.; Liu, F.-X.; Zhang, H. Largely enhanced thermal conductivity of graphene/copper composites with highly aligned graphene network. Carbon 2018, 127, 102-112. [CrossRef]

97. Chu, K.; Wang, X.-H.; Li, Y.-B.; Huang, D.-J.; Geng, Z.-R.; Zhao, X.-L.; Liu, H.; Zhang, H. Thermal properties of graphene/metal composites with aligned graphene. Mater. Des. 2018, 140, 85-94. [CrossRef]

98. Gao, X.; Yue, H.; Guo, E.; Zhang, H.; Lin, X.; Yao, L.; Wang, B. Mechanical properties and thermal conductivity of graphene reinforced copper matrix composites. Powder Technol. 2016, 301, 601-607. [CrossRef]

99. El-Kady, O.; Yehia, H.M.; Nouh, F. Preparation and characterization of Cu/(WC-TiC-Co)/graphene nano-composites as a suitable material for heat sink by powder metallurgy method. Int. J. Refract. Met. Hard Mater. 2019, 79, 108-114. [CrossRef]

100. You, J.H.; Brindel, A.; Nawka, S.; Schubert, T.; Kieback, B. Thermal and mechanical properties of infiltrated W/CuCrZr composite materials for functionally graded heat sink application. J. Nucl. Mater. 2013, 438, 1-6. [CrossRef]

101. Reddy, M.P.; Shakoor, R.A.; Parande, G.; Manakari, V.; Ubaid, F.; Mohamed, A.M.A.; Gupta, M. Enhanced performance of nanosized $\mathrm{SiC}$ reinforced $\mathrm{Al}$ metal matrix nanocomposites synthesized through microwave sintering and hot extrusion techniques. Prog. Nat. Sci. Mater. Int. 2017, 27, 606-614. [CrossRef]

102. Ruch, P.W.; Beffort, O.; Kleiner, S.; Weber, L.; Uggowitzer, P.J. Selective interfacial bonding in Al(Si)-diamond composites and its effect on thermal conductivity. Compos. Sci. Technol. 2006, 66, 2677-2685. [CrossRef] 
103. Shu, S.; Yang, H.; Tong, C.; Qiu, F. Fabrication of TiCx-TiB2/Al composites for application as a heat sink. Materials 2016, 9, 642. [CrossRef] [PubMed]

104. Smith, L.J.B.; Corbin, S.F.; Hexemer, R.L.; Donaldson, I.W.; Bishop, D.P. Development and processing of novel aluminum powder metallurgy materials for heat sink applications. Metall. Mater. Trans. A Phys. Metall. Mater. Sci. 2014, 45, 980-989. [CrossRef]

105. Tayebi, M.; Jozdani, M.; Mirhadi, M. Thermal expansion behavior of Al-B4C composites by powder metallurgy. J. Alloy. Compd. 2019, 809, 151753. [CrossRef]

106. Wang, P.; Xiu, Z.; Jiang, L.; Chen, G.; Lin, X.; Wu, G. Enhanced thermal conductivity and flexural properties in squeeze casted diamond/aluminum composites by processing control. Mater. Des. 2015, 88, 1347-1352. [CrossRef]

107. Manivannan, A.; Sasikumar, R.; Joshuva, R.; Singh, D. Thermal Investigation of Aa 6061 Based Particulate. Int. J. Mech. Prod. Eng. 2017, 5, 2320-2322.

108. Abedinzadeh, R.; Safavi, S.M.; Karimzadeh, F. A study of pressureless microwave sintering, microwave-assisted hot press sintering and conventional hot pressing on properties of aluminium/alumina nanocomposite. J. Mech. Sci. Technol. 2016, 30, 1967-1972. [CrossRef]

109. Elomari, S.; Boukhili, R.; San Marchi, C.; Mortensen, A.; Lloyd, D.J. Thermal expansion responses of pressure infiltrated SiC/Al metal-matrix composites. J. Mater. Sci. 1997, 32, 2131-2140. [CrossRef]

110. Sidhu, S.S.; Singh, M.; Singh Bains, P. On the thermal conductivity of bimodal SiC/A356 composites fabricated via powder metallurgy route. Part. Sci. Technol. 2018, 36, 324-331. [CrossRef]

111. Saraswati, R.; Polese, F.J. Aluminum matrix composite heat sinks for microchips and microcircuits. In Proceedings of the Proceedings of SPIE-The International Society for Optical Engineering, San Diego, CA, USA, 1-4 November 1998; pp. 681-686.

112. Zhang, Q.; Wu, G.; Jiang, L.; Chen, G. Thermal expansion and dimensional stability of Al-Si matrix composite reinforced with high content SiC. Mater. Chem. Phys. 2003, 82, 780-785. [CrossRef]

113. Manivannan, A.; Sasikumar, R. Fabrication and Characterization of Aluminium Boron Nitride Composite for Fins. Mater. Today Proc. 2018, 5, 8618-8624. [CrossRef]

114. Matli, P.R.; Ubaid, F.; Shakoor, R.A.; Parande, G.; Manakari, V.; Yusuf, M.; Amer Mohamed, A.M.; Gupta, M. Improved properties of Al-Si3N4 nanocomposites fabricated through a microwave sintering and hot extrusion process. RSC Adv. 2017, 7, 34401-34410. [CrossRef]

115. Zhang, Q.; Chen, G.; Wu, G.; Xiu, Z.; Luan, B. Property characteristics of a AlNp/Al composite fabricated by squeeze casting technology. Mater. Lett. 2003, 57, 1453-1458. [CrossRef]

116. Feng, H.; Yu, J.K.; Tan, W. Microstructure and thermal properties of diamond/aluminum composites with TiC coating on diamond particles. Mater. Chem. Phys. 2010, 124, 851-855. [CrossRef]

117. Ma, L.; Zhang, L.; Zhao, P.; Hu, N.; Gong, Z.; Ye, W.; Wei, Q.; Zhou, K.; Yu, Z.; Zhang, Y. A new design of composites for thermal management: Aluminium reinforced with continuous CVD diamond coated W spiral wires. Mater. Des. 2016, 101, 109-116. [CrossRef]

118. Schöbel, M.; Degischer, H.P.; Vaucher, S.; Hofmann, M.; Cloetens, P. Reinforcement architectures and thermal fatigue in diamond particle-reinforced aluminum. Acta Mater. 2010, 58, 6421-6430. [CrossRef]

119. Beffort, O.; Khalid, F.A.; Weber, L.; Ruch, P.; Klotz, U.E.; Meier, S.; Kleiner, S. Interface formation in infiltrated Al(Si)/diamond composites. Diam. Relat. Mater. 2006, 15, 1250-1260. [CrossRef]

120. Khalid, F.A.; Beffort, O.; Klotz, U.E.; Keller, B.A.; Gasser, P. Microstructure and interfacial characteristics of aluminium-diamond composite materials. Diam. Relat. Mater. 2004, 13, 393-400. [CrossRef]

121. Johnson, W.B.; Sonuparlak, B. Diamond/Al metal matrix composites formed by the pressureless metal infiltration process. J. Mater. Res. 1993, 8, 1169-1173. [CrossRef]

122. Liang, X.; Jia, C.; Chu, K.; Chen, H. Predicted interfacial thermal conductance and thermal conductivity of diamond/Al composites with various interfacial coatings. Rare Met. 2011, 30, 544-549. [CrossRef]

123. Yang, B.; Yu, J.-K.; Chen, C. Microstructure and thermal expansion of Ti coated diamond/Al composites. Trans. Nonferrous Met. Soc. China 2009, 19, 1167-1173. [CrossRef]

124. Che, Z.; Li, J.; Wang, Q.; Wang, L.; Zhang, H.; Zhang, Y.; Wang, X.; Wang, J.; Kim, M.J. The formation of atomic-level interfacial layer and its effect on thermal conductivity of $\mathrm{W}$-coated diamond particles reinforced $\mathrm{Al}$ matrix composites. Compos. Part A Appl. Sci. Manuf. 2018, 107, 164-170. [CrossRef]

125. Monje, I.E.; Louis, E.; Molina, J.M. Optimizing thermal conductivity in gas-pressure infiltrated aluminum/diamond composites by precise processing control. Compos. Part A Appl. Sci. Manuf. 2013, 48, 9-14. [CrossRef]

126. Zhang, Y.; Li, J.; Zhao, L.; Wang, X. Optimisation of high thermal conductivity Al/diamond composites produced by gas pressure infiltration by controlling infiltration temperature and pressure. J. Mater. Sci. 2014, 50, 688-696. [CrossRef]

127. Chen, J.K.; Huang, I.S. Thermal properties of aluminum-graphite composites by powder metallurgy. Compos. Part B Eng. 2013, 44, 698-703. [CrossRef]

128. Liu, X.; Wang, W.; Wang, D.; Xiao, B.; Ni, D.; Chen, L.; Ma, Z. Effect of Graphite Flake Size on the Strength and Thermal Conductivity of Graphite Flakes/Al Composites. Jinshu Xuebao Acta Metall. Sin. 2017, 53, 869-878. [CrossRef]

129. Oddone, V.; Boerner, B.; Reich, S. Composites of aluminum alloy and magnesium alloy with graphite showing low thermal expansion and high specific thermal conductivity. Sci. Technol. Adv. Mater. 2017, 18, 180-186. [CrossRef] 
130. Fukuchi, K.; Sasaki, K.; Katagiri, K.; Imanishi, T.; Kakitsuji, A. Aluminium based high thermal conductive composites containing CNT and VGCF-deformation dependence of thermal conductivity. Procedia Eng. 2011, 10, 912-917. [CrossRef]

131. Kurita, H.; Feuillet, E.; Guillemet, T.; Heintz, J.M.; Kawasaki, A.; Silvain, J.F. Simple fabrication and characterization of discontinuous carbon fiber reinforced aluminum matrix composite for lightweight heat sink applications. Acta Metall. Sin. 2014, 27, 714-722. [CrossRef]

132. Pei, R.; Chen, G.; Wang, Y.; Zhao, M.; Wu, G. Effect of interfacial microstructure on the thermal-mechanical properties of mesophase pitch-based carbon fiber reinforced aluminum composites. J. Alloy. Compd. 2018, 756, 8-18. [CrossRef]

133. Tokunaga, T.; Takahashi, K.; Ohno, M.; Sasaki, K.; Imanishi, T.; Matsuura, K. Fabrication of Carbon Fiber Oriented Al-Based Composites by Hot Extrusion and Evaluation of Their Thermal Conductivity. J. Jpn. Inst. Met. 2016, 80, 640-645. [CrossRef]

134. Zhang, L.; Wei, Q.; An, J.; Ma, L.; Zhou, K.; Ye, W.; Yu, Z.; Gan, X.; Lin, C.T.; Luo, J. Construction of 3D interconnected diamond networks in Al-matrix composite for high-efficiency thermal management. Chem. Eng. J. 2020, 380. [CrossRef]

135. Beronská, N.; Iždinský, K.; Štefánik, P.; Kúdela, S.; Simancík, F.; Vávra, I.; Križanová, Z. Structure and thermal expansion behaviour of $\mathrm{Al} / \mathrm{C}$ composites reinforced with unidirectionally aligned continuous high modulus $\mathrm{C}$ fibres. Kov. Mater. 2011, 49, 427-436. [CrossRef]

136. Lee, M.; Choi, Y.; Sugio, K.; Matsugi, K.; Sasaki, G. Effect of aluminum carbide on thermal conductivity of the unidirectional $\mathrm{CF} / \mathrm{Al}$ composites fabricated by low pressure infiltration process. Compos. Sci. Technol. 2014, 97, 1-5. [CrossRef]

137. Wu, J.; Zhang, H.; Zhang, Y.; Wang, X. Mechanical and thermal properties of carbon nanotube/aluminum composites consolidated by spark plasma sintering. Mater. Des. 2012, 41, 344-348. [CrossRef]

138. Zhang, L.; Hou, G.; Zhai, W.; Ai, Q.; Feng, J.; Zhang, L.; Si, P.; Ci, L. Aluminum/graphene composites with enhanced heatdissipation properties by in-situ reduction of graphene oxide on aluminum particles. J. Alloy. Compd. 2018, 748, 854-860. [CrossRef]

139. Molina, J.M.; Louis, E. Anisotropy in thermal conductivity of graphite flakes-SiCp/matrix composites: Implications in heat sinking design for thermal management applications. Mater. Charact. 2015, 109, 107-115. [CrossRef]

140. Chamroune, N.; Delange, F.; Caillault, N.; Morvan, F.; Lu, Y.; Kawasaki, A.; Silvain, J.F. Synergetic Effect of Discontinuous Carbon Fibers and Graphite Flakes on Thermo-Mechanical Properties of Aluminum Matrix Composites Fabricated by Solid-Liquid Phase Sintering. Met. Mater. Int. 2020, 26, 155-167. [CrossRef]

141. Peng, X.; Huang, Y.; Han, X.; Fan, R.; Liu, X. High volume fraction of copper coated graphite flake $\backslash$ Nitrogen doped carbon fiber reinforced aluminum matrix composites. J. Alloy. Compd. 2020, 822, 153584. [CrossRef]

142. Xue, C.; Yu, J.K.; Zhu, X.M. Thermal properties of diamond/SiC/Al composites with high volume fractions. Mater. Des. 2011, 32, 4225-4229. [CrossRef]

143. Han, X.; Huang, Y.; Peng, X.; Gao, X.; Li, T.; Liu, P. 3D continuous copper networks coated with graphene in Al-matrix composites for efficient thermal management. Compos. Struct. 2021, 258, 113177. [CrossRef]

144. Zhao, C.; Gao, J.Z. Thermal conductivity of diamond/Ag composites with chromium carbide coated diamonds for the building materials of high power modules. Mater. Sci. Technol. 2014, 30, 800-805. [CrossRef]

145. Pal, H.; Sharma, V. Thermal conductivity of carbon nanotube-silver composite. Trans. Nonferrous Met. Soc. China 2015, $25,154-161$. [CrossRef]

146. Molina-Jordá, J.M. Nano- and micro-/meso-scale engineered magnesium/diamond composites: Novel materials for emerging challenges in thermal management. Acta Mater. 2015, 96, 101-110. [CrossRef]

147. Hou, L.G.; Wu, R.Z.; Wang, X.D.; Zhang, J.H.; Zhang, M.L.; Dong, A.P.; Sun, B.D. Microstructure, mechanical properties and thermal conductivity of the short carbon fiber reinforced magnesium matrix composites. J. Alloy. Compd. 2017, 695, 2820-2826. [CrossRef]

148. Parsonage, T. Beryllium metal matrix composites for aerospace and commercial applications. In Materials Science and Technology; IOM Communications Ltd.: London, UK, 2000; Volume 16, pp. 732-738.

149. Zeng, C.; Shen, J.; Zhang, J. High thermal conductivity in indium-based metal/diamond composites by good wettability of diamond with indium. Diam. Relat. Mater. 2021, 112, 108230. [CrossRef]

150. Delannay, F.; Colin, C.; Marchal, Y.; Tao, L.; Boland, F.; Cobzaru, P.; Lips, B.; Dellis, M.A. Processing and properties of metal matrix composites reinforced with continuous fibers for the control of thermal expansion, creep resistance and fracture toughness. J. Phys. 1993, 3, 1675-1684. [CrossRef]

151. Kaczmar, J.W.; Pietrzak, K.; Wlosiński, W. Production and application of metal matrix composite materials. J. Mater. Process. Technol. 2000, 106, 58-67. [CrossRef]

152. Cook, A.J.; Werner, P.S. Pressure infiltration casting of metal matrix composites. Mater. Sci. Eng. A 1991, 144, 189-206. [CrossRef]

153. Bai, G.; Li, N.; Wang, X.; Wang, J.; Kim, M.J.; Zhang, H. High thermal conductivity of Cu-B/diamond composites prepared by gas pressure infiltration. J. Alloy. Compd. 2018, 735, 1648-1653. [CrossRef]

154. Li, J.; Zhang, H.; Zhang, Y.; Che, Z.; Wang, X. Microstructure and thermal conductivity of Cu/diamond composites with Ti-coated diamond particles produced by gas pressure infiltration. J. Alloy. Compd. 2015, 647, 941-946. [CrossRef]

155. Li, N.; Wang, L.; Dai, J.; Wang, X.; Wang, J.; Kim, M.J.; Zhang, H. Interfacial products and thermal conductivity of diamond/Al composites reinforced with ZrC-coated diamond particles. Diam. Relat. Mater. 2019, 100, 107565. [CrossRef]

156. Dobrzañski, L.A.; Kremzer, M.; Nowak, A.J.; Nagel, A. Aluminium matrix composites fabricated by infiltration method. Arch. Mater. Sci. Eng. 2009, 36, 5-11. 
157. Zheng, R.R.; Wu, Y.; Liao, S.L.; Wang, W.Y.; Wang, W.B.; Wang, A.H. Microstructure and mechanical properties of Al/(Ti,W)C composites prepared by microwave sintering. J. Alloy. Compd. 2014, 590, 168-175. [CrossRef]

158. Ruskola, M. Numerical Modelling of Pulsed Electric Current Sintering Process. Master's Thesis, Aalto University, Espoo, Finland, 2014.

159. Kruszewski, M.; Zybala, R.; Ciupinski, L.; Chmielewski, M.; Adamczyk-Cieślak, B.; Michalski, A.; Rajska, M.; Kurzydlowski, K. Microstructure and Thermoelectric Properties of Bulk Cobalt Antimonide (CoSb3) Skutterudites Obtained by Pulse Plasma Sintering. J. Electron. Mater. 2016, 45, 1369-1376. [CrossRef]

160. Ghasali, E.; Alizadeh, M.; Niazmand, M.; Ebadzadeh, T. Fabrication of magnesium-boron carbide metal matrix composite by powder metallurgy route: Comparison between microwave and spark plasma sintering. J. Alloy. Compd. 2017, 697, 200-207. [CrossRef] 